\title{
Molecular Dynamics Simulation of Nanoscale Machining
}

\author{
Akinjide Oluwajobi \\ Obafemi Awolowo University, Ile-Ife \\ Nigeria
}

\section{Introduction}

Product miniaturization is a major motivation for the development of ultra-precision technologies and processes which can achieve high form and excellent surface finish. Of all the available manufacturing approaches, mechanical nanometric machining is still a good option for machining complex 3D devices in a controllable way (Jackson, 2008). As the dimension goes down to the nanoscale, the machining phenomena take place in a limited region of tool-workpiece interface. At this length scale and interface, the material removal mechanisms are not fully understood, so more insight is needed, which on the long run will help to achieve high precision manufacturing with predictability, repeatability and productivity (Luo, 2004). At present, it is very difficult to observe the diverse microscopic physical phenomena occurring through experiments at the nanoscale (Rentsch, 2008). Subsequently, the other alternative is to explore available simulation techniques. Continuum mechanics approach is not adequate, as the point of interest/interface cannot be assumed to be homogeneous, but rather discrete, so, atomistic simulation methods are the suitable techniques for modelling at the nanoscale.

The aim of this chapter is to review the use of classical molecular dynamics (MD) method for nanoscale machining. The steps on how the MD method can be applied to model nanometric machining and the importance of choosing appropriate interatomic potentials for the simulation are considered. Also, some examples of MD simulation of nanoscale machining are presented.

\section{The MD method}

Molecular dynamics (MD) is a computer simulation technique used in the study of the motions of a set of particles - atoms and molecules (Allen \& Tildesley, 1988; Haile, 1997; Field, 1999; Frenkel \& Smit, 2001; Leach, 2001; Schlick, 2002; Rapaport, 2004). The technique works by following the time evolution of a set of interacting atoms while integrating the equations of their motion. It is employed to study the classical motion of a system and then to extract experimental observables from the dynamics (Turkerman \& Martyna, 2000). The MD is deterministic; once the positions, velocities and accelerations of the particles are known, the state of the system can be predicted. The method is also based on statistical mechanics - a way to obtain a set of configurations distributed according to some statistical distribution functions (Ercolessi, 1997, Hernandez, 2008). 


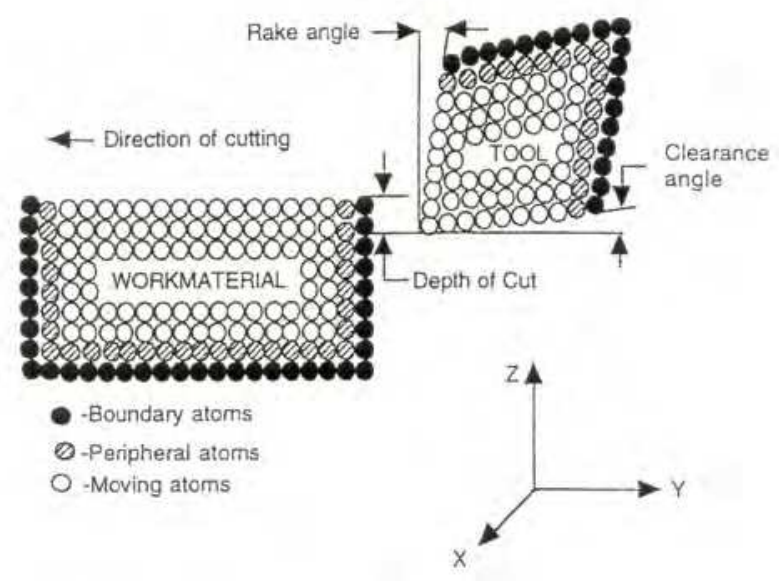

Fig. 1. Schematic of the MD Simulation of Nanometric Cutting (2D) (Komanduri \& Raff, 2001)

The MD method was initiated in the late 1950s at Lawrence Radiation Laboratory in the US by Alder and Wainwright in the study of interactions of hard spheres (Alder \& Wainwright, 1957, 1959). Gibson et al., 1961, carried out probably the first MD calculations with a continuous potential based on a finite difference time integration method. In 1964, Rahman carried out the simulation of liquid argon by using a realistic potential (Rahman, 1964). Later on, the first MD simulation of a realistic system was conducted by (Stillinger \& Rahman, 1974) in 1974. Since then, the use of the simulation method has spread from Physics to Materials Science and now to Mechanical Engineering and other disciplines.

In the field of nanometric cutting, Belak pioneered work on the study of cutting copper with a diamond tool (Belak \& Stowers, 1990). Initially, the method was used extensively to model indentation and cutting. Figure 1 shows the schematic of the MD simulation of nanoscale cutting. In 1991, Belak and Stowers first applied the MD to abrasive processes (Belak \& Stowers, 1991) and Rentsch and Inasaki's study later presented the first results of simulations targeted on the pile-up phenomenon in abrasive machining (Rentsch \& Inasaki, 1994). The MD method has been used in a variety of other application areas, namely; indentation (Kenny \& Mulliah, 2005, Smith et al., 2003), wear and friction (Cheng et al., 2003, Shimizu et al., 1998), void growth (Potirniche et al., 2006, Zhao et al., 2009), etcetera.

The MD simulation is based on Newton's second law of motion. It consists of the numerical step-by-step integration of the classical equations of motion. For a set of $\mathrm{N}$ atoms,

$$
F_{i}=m_{i} a_{i}
$$

Where $m_{i}$ is the mass of atom i, $a_{i}=\frac{d^{2} r_{i}}{d t^{2}}$ is the acceleration of the atom $\mathrm{i}$ and $F_{i}$ is the resultant force acting on atom i. These forces should be balanced by the potential energy between atoms, which are usually presented as the gradient of a potential energy function. 


\subsection{Thermodynamic ensembles}

In MD simulations, various thermodynamic ensembles are employed. An ensemble is a large group of atoms or systems which are in different microscopic states, but have the same macroscopic or thermodynamic states. If a system of $\mathrm{N}$ atoms in a given macrostate is defined in terms of thermodynamic quantities, number of atoms, N; pressure, $\mathrm{P}$; temperature, T; entropy, S; volume, $\mathrm{V}$ etc, there are many configurations at the atomic scale, which will lead to the same macrostate. The microstate of a system, defined by the atomistic positions and momenta cannot be known in a deterministic manner, because of the uncertainty principle of quantum mechanics. To avoid this problem, statistical mechanics approach is used for the atomic description.

The commonly used ensembles are the following, namely;

Microcanonical Ensemble (NVE)

This is an isolated system, with $\mathrm{N}$ atoms, which occupies a constant volume and the overall energy, $\mathrm{E}$ of the system is constant.

Canonical Ensemble (NVT)

This is a system in a temperature bath, with $\mathrm{N}$ atoms; and the volume, $\mathrm{V}$ and the temperature, $\mathrm{T}$ of the system are kept constant.

Isobaric Isothermal Ensemble (NPT)

This is a system in a temperature and pressure bath, with $\mathrm{N}$ atoms; and the pressure, $\mathrm{P}$ and the temperature, $\mathrm{T}$ of the system are kept constant.

\section{Grand Canonical Ensemble ( $\mu$ VT)}

This is a system with a constant chemical potential and temperature $\mathrm{T}$.

\subsection{Steps in MD simulation}

The outline of the MD simulation is as follows:

- $\quad$ Select the model

- Choose an appropriate interatomic potential

- Choose the algorithm for the integration of the equations of motion

- Initialize the model

- Relax the model from its initial state to its dynamically equilibrium condition

- Run the simulation and analyze the results

\subsubsection{Select the model}

The model should be selected correctly to reproduce what is expected (whether 2D/3D). The level of details and accuracy needed should guide this decision.

\subsubsection{Choose an appropriate interatomic potential}

Then, the next thing is a major task in MD simulation, which is the selection of the potential function for the atomic interactions. This is a function, $V\left(r_{i}, \ldots \ldots \ldots . . r_{N}\right)$ of the position of the 
nuclei which represents the potential energy of the system. Where $\left(r_{i}\right.$, .$\left.r_{N}\right)$ represents the complete co-ordinate position of the atoms. Then forces are derived from it as,

$$
F_{i}=-\frac{\partial}{\partial r_{i}} V\left(r_{i}, \ldots \ldots \ldots r_{N}\right)
$$

Strictly speaking, the problem of modelling a material is that of finding a potential function for that material. If the potential function doesn't model the atomic behaviour correctly, the results produced from the simulation would be wrong. Consider the energy of $\mathrm{N}$ interacting particles, which can be written as (Tersoff, 1988);

$$
E=\sum_{i} V_{1}\left(r_{i}\right)+\sum_{i<j} V_{2}\left(r_{i}, r_{j}\right)+\sum_{i<j<k} V_{3}\left(r_{i}, r_{j}, r_{k}\right)+\ldots \ldots .+\sum_{i<j<k \ldots \ldots<N} V_{N}\left(r_{i}, r_{j}, r_{k} \ldots \ldots . r_{N}\right)
$$

Where $r_{i}, r_{j}, r_{k}$ are the positions of the particles and the functions $V_{1}, V_{2}, V_{3}, \ldots . V_{N}$ are the mbody potentials.

From equation (3), the second term, $\sum_{i<j} V_{2}\left(r_{i}, r_{j}\right)$ is the two-body or pair potential and the third term is the three-body potential and so on. The pair potentials are the simplest interatomic potentials used for the interaction of a set of particles. The most popularly used is the LennardJones potential; others are Morse potential, Born-Mayer potential and et cetera. Apart from the pair potentials, there are multi-body potentials, like Tersoff and Embedded-Atom Method (EAM) potentials. The following is a consideration of some widely used interatomic potentials.

Lennard-Jones Potential (Lennard-Jones, 1924)

$$
V_{i j}=4 \varepsilon\left[\left(\frac{\sigma}{r}\right)^{12}-\left(\frac{\sigma}{r}\right)^{6}\right]
$$

Where $\varepsilon$ and $\sigma$ are constants which are dependent on the interacting particles. The LJ potential is ideal for rare gases, where the interactions between the non- bonded and uncharged atoms are due to weak van der Waal forces.

Morse Potential (Morse, 1929)

$$
V_{i j}=D\left\{\exp \left[-2 \alpha\left(r_{i j}-r_{e}\right)\right]-2 \exp \left[-\alpha\left(r_{i j}-r_{e}\right]\right\}\right.
$$

Where, $r_{i j}$ and $r_{e}$ are instantaneous and equilibrium distances between atoms $i$ and $j$ respectively; $\alpha$ and D are constants determined on the basis of the physical properties of the material. The Morse potential is suitable for cubic metals and they can be used to model the interactions between an atom and a surface.

\section{Born-Mayer Potential}

Born and Mayer suggested that the repulsion between the atoms would have a roughly exponential dependence on distance (Born \& Mayer, 1932).

$$
\left.V_{i j}=A\left\{\exp \left[-\frac{r}{a_{B M}}\right)\right]\right\}
$$


Where A and $a_{B M}$ are constants dependent on the material. This potential is used for metals, Group III-V semiconductors and ceramics.

\section{Tersoff Potential}

Tersoff modelled the total energy of the system as a sum of pair like interactions and as a function of the atomic coordinates, given as equation (7). The potential is based on the concept that the strength of a bond between two atoms is not a constant, but depends on the local environment (Tersoff, 1988a ,1988b).

$$
E=\sum_{i} E_{i}=\frac{1}{2} \sum_{i} \sum_{i \neq j} V_{i j}
$$

and

$$
V_{i j}=f_{C}\left(r_{i j}\right)\left[a_{i j} f_{R}\left(r_{i j}\right)+b_{i j} f_{A}\left(r_{i j}\right)\right]
$$

$$
\begin{aligned}
& \text { where } \\
& f_{R}(r)=A \exp \left(-\lambda_{1} r\right), \\
& f_{A}(r)=-B \exp \left(-\lambda_{2} r\right) \text {, } \\
& f_{C}(r)=\left\{\begin{array}{l}
1, r<R-D \\
\frac{1}{2}-\frac{1}{2} \sin \left[\frac{\pi}{2}(r-R) / D\right], R-D<r<R+D, \\
0, r>R+D
\end{array}\right. \\
& b_{i j}=\left(1+\beta^{n} \zeta_{i j}^{n}\right)^{-1 / 2 n} \text {, } \\
& \zeta_{i j}=\sum_{k(\neq i, j)} f_{C}\left(r_{i k}\right) g\left(\theta_{i j k}\right) \exp \left[\lambda_{3}^{3}\left(r_{i j}-r_{i k}\right)^{3}\right] \text {, } \\
& g(\theta)=1+\frac{p^{2}}{q^{2}}-\frac{p^{2}}{\left[q^{2}+(h-\cos \theta)^{2}\right]}, \\
& a_{i j}=\left(1+\alpha^{n} \eta_{i j}^{n}\right)^{-1 / 2 n} \text {, } \\
& \eta_{i j}=\sum_{k(\neq i, j)} f_{C}\left(r_{i k}\right) \exp \left[\lambda_{3}^{3}\left(r_{i j}-r_{i k}\right)^{3}\right]
\end{aligned}
$$

Where $\mathrm{R}$ and $\mathrm{D}$ are cutoff parameters; $\mathrm{A}, \mathrm{B}, \lambda_{1}, \lambda_{2}, \lambda_{3}, \alpha, \beta, \mathrm{n}, \mathrm{p}, \mathrm{q}, \mathrm{h}$ are fitting parameters of the Tersoff potential.

The Tersoff potential is used for covalently bonded materials like silicon and carbon atoms.

Embedded-Atom Method (EAM) Potential 
For the EAM potential, the total energy of the system can be written as (Foiles ,1985, Foiles et al., 1986).

$$
E_{\text {tot }}=\sum_{i} G_{i}\left(\rho_{h, i}\right)+\frac{1}{2} \sum_{i, j} V_{i j}\left(r_{i j}\right)
$$

$\rho_{h, i}$ is the total electron density at atom i due to the rest of the atoms in the system.

$G_{i}$ is the embedding energy for placing an atom into the electron density

$V_{i, j}$ is the short range pair interaction representing the core-core repulsion

$r_{i j}$ is the separation of atoms $\mathrm{i}$ and $\mathrm{j}$

The EAM potential was developed for a wide range of metals. It incorporates an approximation for the many-atom interactions neglected by the pair-potential scheme.

\section{Modified Embedded-Atom Method (MEAM) Potential}

The MEAM is theoretically an extension of the EAM potential (Baskes, 1992) with modifications to include the directionality of the bonding. The bond-angle was explicitly handled so as to accommodate covalent systems. The total energy is given by (Equation 9). The MEAM is suitable for modelling metals and alloys with fcc, bcc, hcp and cubic structures, and also for covalent materials such as silicon and carbon (Oluwajobi \& Chen, 2010a).

The list of the potentials is not exhaustive; and there are other potentials which are modified forms of the ones already discussed. To obtain physically meaningful results from atomistic simulations, it is essential that reliable interatomic potentials are used. A reliable potential would reproduce various physical properties of the relevant elements or alloys, including the elastic, structural, defect, surface and thermal properties etc (Lee et al., 2005). For example, Tersoff potential was designed for the description of covalent materials like silicon, germanium, carbon, silicon carbide etc. and it cannot adequately model metals. Also, the EAM potential was designed for metals, as it describes the bonding in metals more satisfactorily, but the MEAM potential can be used for the modelling of both metallic systems and covalently bonded materials. Table 1 shows some interatomic potentials and their suitability (Oluwajobi \& Chen, 2010).

It should be stated that EAM and MEAM potentials should be used for metals, where appropriate; Tersoff and MEAM potentials should be used for covalent materials, and for the interface of materials where suitable potentials are not available, appropriate existing potentials like LJ and Morse can be used with caution.

\subsubsection{Algorithms for the Integration of the Equations of Motion}

The next step, after choosing the interatomic potential/s is to select an appropriate algorithm for the integration of the Newton's equations of motions. This is to numerically solve for positions and velocities at a time, $t$ and at a later time, $t+\Delta t$. (Generally, the algorithm is already chosen in the MD software that one uses for the simulation). MD simulations use time steps from a few femto seconds $\left(10^{-15} \mathrm{~s}\right)$ (Shimada et al., 1993). If a large time step is used, the computational time is reduced, but when the time step is too large, this can cause instability and inaccuracy in the solutions. 


\begin{tabular}{|c|c|c|}
\hline Name & Model & Application \\
\hline $\begin{array}{l}\text { Lennard- } \\
\text { Jones } \\
\text { Potential }\end{array}$ & $\begin{array}{l}V_{i j}=4 \varepsilon\left[\left(\frac{\sigma}{r}\right)^{12}-\left(\frac{\sigma}{r}\right)^{6}\right], \sigma \text { and } \varepsilon \text { are constants which are } \\
\text { dependent on the physical property of the materials. } \\
\text { (Lennard-Jones, 1924) }\end{array}$ & $\begin{array}{l}\text { Mostly suitable } \\
\text { for rare gases }\end{array}$ \\
\hline $\begin{array}{l}\text { Morse } \\
\text { Potential }\end{array}$ & $\begin{array}{l}V_{i j}=D\left\{\exp \left[-2 \alpha\left(r_{i j}-r_{e}\right)\right]-2 \exp \left[-\alpha\left(r_{i j}-r_{e}\right]\right\}\right. \\
r_{i j} \text { and } r_{e} \text { are instantaneous and equilibrium distances } \\
\text { between atoms } i \text { and } j \text { respectively } \alpha \text { and D are constants } \\
\text { determined on the basis of the physical properties of the } \\
\text { material (Morse, 1929) }\end{array}$ & $\begin{array}{l}\text { Mostly suitable } \\
\text { for cubic metals }\end{array}$ \\
\hline $\begin{array}{l}\text { Born-Mayer } \\
\text { Potential }\end{array}$ & $\begin{array}{l}V_{i j}=A\left\{\exp \left[-2 \alpha\left(r_{i j}-r_{0}\right)\right]\right\} \\
\text { A and } r_{0} \text { are constants dependent on the material (Born \& } \\
\text { Mayer, 1932) }\end{array}$ & $\begin{array}{l}\text { Mostly suitable } \\
\text { for ceramics }\end{array}$ \\
\hline $\begin{array}{l}\text { Tersoff } \\
\text { Potential }\end{array}$ & $\begin{array}{l}V_{i j}=V_{r}\left(r_{i j}\right)-B_{i j} V_{a}\left(r_{i j}\right) \\
V_{r} \text { and } V_{a} \text { are the potentials due to repulsive and attractive } \\
\text { forces between atoms } i \text { and } j \text { and } B_{i j} \text { is a parameter that } \\
\text { provides the information for the direction and the length of } \\
\text { the bond. (Tersoff 1988a, 1988b) }\end{array}$ & $\begin{array}{l}\text { Mostly suitable } \\
\text { for covalently } \\
\text { bonded } \\
\text { materials }\end{array}$ \\
\hline $\begin{array}{l}\text { Embedded- } \\
\text { Atom } \\
\text { Potential } \\
\text { (EAM) }\end{array}$ & $\begin{array}{l}E_{t o t}=\sum_{i} G_{i}\left(\rho_{h, i}\right)+\frac{1}{2} \sum_{i, j} V_{i j}\left(r_{i j}\right) \\
\rho_{h, i} \text { is the total electron density at atom } \mathrm{i} \text { due to the rest of } \\
\text { the atoms in the system. } \\
G_{i} \text { is the embedding energy for placing an atom into the } \\
\text { electron density } \\
V_{i, j} \text { is the short range pair interaction representing the core- } \\
\text { core repulsion } \\
r_{i j} \text { is the separation of atoms } \mathrm{i} \text { and } \mathrm{j} \\
\text { (Foiles } 1985, \text { Foiles et al., } 1986 \text { ) }\end{array}$ & $\begin{array}{l}\text { Mostly suitable } \\
\text { for a wide } \\
\text { range of metals }\end{array}$ \\
\hline
\end{tabular}

Table 1. Comparison of the Interatomic Potentials (Oluwajobi \& Chen, 2010a)

Many numerical schemes have been developed for the integration of the equations of motions. Some of these are the Verlet algorithm (Verlet, 1967), the predictor-corrector 
algorithm (Rahman, 1964, Gear \& Tu, 1974, Gear \& Watanabe, 1974) and the Beeman's algorithm (Beeman, 1976). All the above integration schemes make the assumption, that the positions, velocities and accelerations can be approximated using a Taylor series expansion:

$$
\begin{aligned}
& \mathrm{r}(\mathrm{t}+\Delta \mathrm{t})=\mathrm{r}(\mathrm{t})+\dot{\mathrm{r}}(\mathrm{t}) \Delta \mathrm{t}+\frac{1}{2} \ddot{\mathrm{r}}(\mathrm{t}) \Delta \mathrm{t}^{2}+\ldots \\
& \mathrm{v}(\mathrm{t}+\Delta \mathrm{t})=\dot{\mathrm{r}}(\mathrm{t})+\ddot{\mathrm{r}}(\mathrm{t}) \Delta \mathrm{t}+\frac{1}{2} \ddot{\mathrm{r}}(\mathrm{t}) \Delta \mathrm{t}^{2}+\ldots \\
& \mathrm{a}(\mathrm{t}+\Delta \mathrm{t})=\ddot{\mathrm{r}}(\mathrm{t})+\cdots \overrightarrow{\mathrm{r}}(\mathrm{t}) \Delta \mathrm{t}+\frac{1}{2} \cdots \\
& \mathrm{r}(\mathrm{t}) \Delta \mathrm{t}^{2}+\ldots
\end{aligned}
$$

Where $\Delta t$ is a finite time step, $r$ is the position, $v$ and $\dot{r}$ are the velocity, a and $\ddot{r}$ are the acceleration; $\ddot{\mathrm{r}}$ and $\ddot{\mathrm{r}}$ are the third and the fourth derivative of position with time.

The Basic Verlet Algorithm (Verlet, 1967)

Using this method, the next step of position can be predicted as follows;

$$
\mathrm{r}(\mathrm{t}+\Delta \mathrm{t})=\mathrm{r}(\mathrm{t})+\mathrm{r}(\mathrm{t}) \Delta \mathrm{t}+\frac{1}{2} \ddot{\mathrm{r}}(\mathrm{t}) \Delta \mathrm{t}^{2}+\ldots
$$

In the same way, the previous step;

$$
\mathrm{r}(\mathrm{t}-\Delta \mathrm{t})=\mathrm{r}(\mathrm{t})-\dot{\mathrm{r}}(\mathrm{t}) \Delta \mathrm{t}+\frac{1}{2} \ddot{\mathrm{r}}(\mathrm{t}) \Delta \mathrm{t}^{2}-\ldots
$$

Summing equations (11) and (12), we have

$$
\mathrm{r}(\mathrm{t}+\Delta \mathrm{t})=2 \mathrm{r}(\mathrm{t})-\mathrm{r}(\mathrm{t}-\Delta \mathrm{t})+\ddot{\mathrm{r}}(\mathrm{t}) \Delta \mathrm{t}^{2}
$$

The method uses no explicit velocities, it is quite straightforward, easy to implement and its storage requirements are modest, but it is not too accurate.

The Verlet Leapfrog Algorithm

In this algorithm, the velocities are calculated by taking the average value halfway between position steps. The equations are as follows;

$$
\begin{gathered}
\mathrm{r}(\mathrm{t}+\Delta \mathrm{t})=\mathrm{r}(\mathrm{t})+\dot{\mathrm{r}}\left(\mathrm{t}+\frac{1}{2} \Delta \mathrm{t}\right) \Delta \mathrm{t} \\
\mathrm{v}\left(\mathrm{t}+\frac{1}{2} \Delta \mathrm{t}\right)=\dot{\mathrm{r}}\left(\mathrm{t}-\frac{1}{2} \Delta \mathrm{t}\right)+\ddot{\mathrm{r}}(\mathrm{t}) \Delta \mathrm{t}
\end{gathered}
$$

In this method, the velocities leap over the positions and then, the positions leap over the velocities. Consequently, the positions and the velocities are not known simultaneously, but the velocities are calculated explicitly.

The Velocity Verlet Algorithm

Using equations deduced from equations (10) and (13), and ignoring infinitesimals, this algorithm calculates new positions, velocities and accelerations using their values at time, $t$. 


$$
\begin{gathered}
\mathrm{r}(\mathrm{t}+\Delta \mathrm{t})=\mathrm{r}(\mathrm{t})+\dot{\mathrm{r}}(\mathrm{t}) \Delta \mathrm{t}+\frac{1}{2} \ddot{\mathrm{r}}(\mathrm{t}) \Delta \mathrm{t}^{2} \\
\mathrm{v}(\mathrm{t}+\Delta \mathrm{t})=\dot{\mathrm{r}}(\mathrm{t})+\frac{1}{2}[\ddot{\mathrm{r}}(\mathrm{t})+\ddot{\mathrm{r}}(\mathrm{t}+\Delta \mathrm{t})] \Delta \mathrm{t}
\end{gathered}
$$

The velocity Verlet algorithm requires low memory.

The Predictor-Corrector Algorithm (Rahman, 1964; Gear \& Tu, 1975; Gear \& Watanabe, 1974)

Velocities at time $t+\Delta t$ are predicted and the forces calculated, and then the corrected forms of the velocities are later calculated. Combining the $r(t+\Delta \mathrm{t})$ and $a(t+\Delta \mathrm{t})$ in equation 10 , the position can be expressed as:

$$
\mathrm{r}(\mathrm{t}+\Delta \mathrm{t})=\mathrm{r}(\mathrm{t})+\dot{\mathrm{r}}(\mathrm{t}) \Delta \mathrm{t}+\frac{2}{3} \ddot{\mathrm{r}}(\mathrm{t}) \Delta \mathrm{t}^{2}-\frac{1}{6} \ddot{\mathrm{r}}(\mathrm{t}-\Delta \mathrm{t}) \Delta \mathrm{t}^{2}+\mathrm{O}\left(\Delta \mathrm{t}^{4}\right)
$$

The velocities at time $\mathrm{t}=\mathrm{t}+\Delta \mathrm{t}$ are then calculated from the positions. Combining the $r(t+\Delta \mathrm{t})$ and $a(t+\Delta \mathrm{t})$ in equation (18), the position can be expressed as:

$$
\text { (Predicted) } \mathrm{v}(\mathrm{t}+\Delta \mathrm{t})=\dot{\mathrm{r}}(\mathrm{t})+\frac{3}{2} \ddot{\mathrm{r}}(\mathrm{t}) \Delta \mathrm{t}-\frac{1}{2} \ddot{\mathrm{r}}(\mathrm{t}-\Delta \mathrm{t}) \Delta \mathrm{t}
$$

The acceleration at $t=t+\Delta t$ are calculated from the positions and the predicted velocities.

$$
\text { (Corrected) } \mathrm{v}(\mathrm{t}+\Delta \mathrm{t})=\dot{\mathrm{r}}(\mathrm{t})+\frac{1}{3} \ddot{\mathrm{r}}(\mathrm{t}+\Delta \mathrm{t}) \Delta \mathrm{t}+\frac{5}{6} \ddot{\mathrm{r}}(\mathrm{t}) \Delta \mathrm{t}-\frac{1}{6} \ddot{\mathrm{r}}(\mathrm{t}-\Delta \mathrm{t}) \Delta \mathrm{t}
$$

This algorithm has the advantage that, by comparing the predicted and the corrected values of parameters, it is possible to perform a self-check on the algorithm for accuracy.

The Beeman's Algorithm

The Beeman's algorithm (Beeman, 1976) is based on equations (21) and (22), which can be deduced from the equations (18) and (20). The algorithm is more complicated and requires more memory than the velocity Verlet, but it provides more accurate expression for the velocities and better energy conservation.

$$
\begin{aligned}
& \mathrm{r}(\mathrm{t}+\Delta \mathrm{t})=\mathrm{r}(\mathrm{t})+\dot{\mathrm{r}}(\mathrm{t}) \Delta \mathrm{t}+\frac{2}{3} \ddot{\mathrm{r}}(\mathrm{t}) \Delta \mathrm{t}^{2}-\frac{1}{6} \ddot{\mathrm{r}}(\mathrm{t}-\Delta \mathrm{t}) \Delta \mathrm{t}^{2} \\
& \mathrm{v}(\mathrm{t}+\Delta \mathrm{t})=\dot{\mathrm{r}}(\mathrm{t})+\dot{\mathrm{r}}(\mathrm{t}) \Delta \mathrm{t}+\frac{7}{6} \ddot{\mathrm{r}}(\mathrm{t}) \Delta \mathrm{t}-\frac{1}{6} \ddot{\mathrm{r}}(\mathrm{t}-\Delta \mathrm{t}) \Delta \mathrm{t}
\end{aligned}
$$

When choosing an integration algorithm following factors need to be considered:

- Accuracy - it should produce an approximate result close to the exact solution

- Memory requirement - it should require little memory

- Efficiency - it should be fast and computationally efficient

- Time Step - it should permit long time step $\Delta \mathrm{t}$ for the integration 


\subsubsection{Initialize the model}

To initialize the simulation, the MD 'box' (the control volume) must be defined; then initial positions and velocities of the atoms must be assigned - this is a kind of initial randomization. Positions of the atoms can be defined, by assuming certain crystal structure and the initial velocities can be randomly assigned.

\subsubsection{Relax the model from its initial state to its dynamically equilibrium condition}

The model has to be relaxed from its artificially assigned initial conditions to its natural, dynamically equilibrium condition, to mimic real materials. This can be achieved by running the MD program under constant temperature for a pre- determined time steps, so that the velocities of atoms that are initially assigned randomly or based on a normal distribution, will gradually reach equilibrium at the specified temperature of the simulation (Cheong et al., 2001). This relaxation time steps will vary, depending on the time needed for the model to reach its natural, dynamically equilibrium state, that is consistent with the environmental temperature.

\subsubsection{Run the simulation and analyze the results}

The simulation is then run and the results analyzed. Using the MD, the effect of such variables as edge effect, depth of cut, velocity and other machining parameters can be defined and the simulations conducted accordingly. It is also easy to vary the properties of the work materials and the cutting tools in MD simulations (Komanduri \& Raff, 2001).

From the results of the simulation, there are various quantities can that be derived for nano machining predictions. Some of which are cutting forces, cutting temperature, potential and kinetic energies, pressure etc.

\subsection{Cutting forces}

In nanometric machining, the cutting forces are the interatomic forces (Luo et al., 2003). These forces are the superposition of the interaction forces between the cutting tool and the workpiece atoms. A low cutting force is as a result of fine cutting conditions, which will in turn decrease the vibration of the cutting system and then result in better surface roughness (Jackson, 2008).

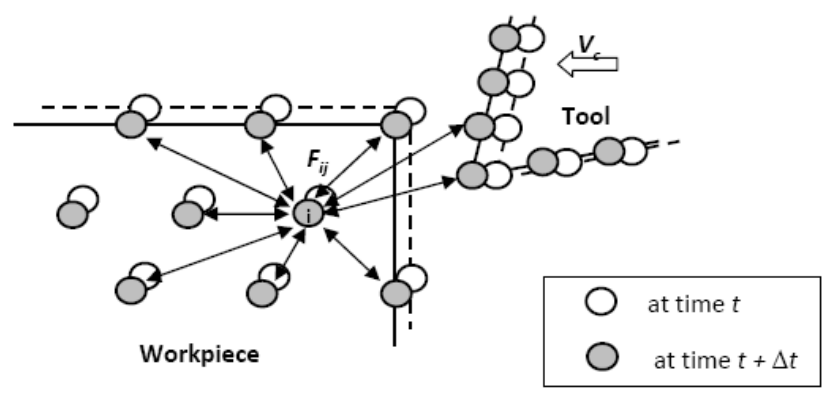

(a)

(b)

Fig. 2. Atomistic Interaction in Nanometric Machining (Ikawa et al., 1991, Promyoo et al., 2008) 
Figure 2 shows the time increment $(\Delta t)$, in which every atom changes its position and interacts with its surrounding neighbour atoms in a manner that is determined from the interatomic potential function.

E.g. for atoms described by Lennard Jones potential, $V_{i j}$, the interatomic force between atoms $i$ and $j$ is

$$
F\left(r_{i j}\right)=-\frac{d V_{i j}}{d r_{i j}}
$$

The force acting on the i-th workpiece atom is thus a summation of the interaction with the surrounding atoms (Luo et al., 2003);

$$
F_{w i}=\sum_{j \neq 1}^{N_{t}} F_{w t i j}+\sum_{j \neq 1}^{N_{w}} F_{w w i j}=\sum_{j \neq 1}^{N_{t}}-\frac{d V\left(r_{w t i j}\right)}{d r_{w t i j}}+\sum_{j \neq 1}^{N_{w w}}-\frac{d V\left(r_{w w i j}\right)}{d r_{w w i j}}
$$

Similarly, the force on each tool atom is

$$
F_{t i}=\sum_{j \neq 1}^{N_{t}} F_{t t i j}+\sum_{j \neq 1}^{N_{w w}} F_{t w i j}=\sum_{j \neq 1}^{N_{t}}-\frac{d V\left(r_{t t i j}\right)}{d r_{t t i j}}+\sum_{j \neq 1}^{N_{w v}}-\frac{d V\left(r_{t w i j}\right)}{d r_{t w i j}}
$$

\subsection{Cutting temperature}

In MD simulations, it is assumed that the cutting energy is totally transferred into cutting heat and this results in an increase of the cutting temperature and kinetic energy of the system.

\subsection{Minimum depth cut}

The Minimum Depth of Cut (MDC) is defined as the minimum undeformed chip thickness that can be removed stably from a work surface at a cutting edge under perfect performance of a machine tool (Ikawa et al., 1992). The concept of MDC is that the depth of cut must be over a certain critical thickness before any chip is formed. This phenomenon of MDC leads to a rising of slipping forces, burr formation and surface roughness (Ducobu et al., 2009). Conventionally, the tool - workpiece material interface has been considered to be homogeneous and continuum mechanics are used in the analysis of the MDC. In nanomachining, analysis is based on discrete atoms whose interactions are governed by appropriate interatomic potentials. The understanding and the accurate prediction of the MDC is very crucial in improving the ultra-precision metal removal technologies, as this would assist in the selection of appropriate machining parameters and optimal geometry design (Oluwajobi \& Chen, 2010b).

\subsection{Nanometric cutting versus conventional cutting mechanics}

Nanometric cutting is based on a very small region of the tool-workpiece interface, which contains few atoms and so discrete mechanics apply. On the other hand, conventional cutting is based on continuum mechanics. The cutting forces are based on the interatomic potentials in nanometric cutting, but they are dependent on the plastic deformation in conventional cutting. Table 2 shows the comparison of nanometric cutting and conventional 
cutting mechanics, and it should be noted that the basic physics of the cutting mechanism on the nanoscale is quite different from that on the macro/conventional scale.

\begin{tabular}{|l|l|l|}
\hline & Nanometric Cutting & Conventional Cutting \\
\hline $\begin{array}{l}\text { Fundamental Cutting } \\
\text { Principles }\end{array}$ & Discrete Molecular Mechanics & Continuum Mechanics \\
\hline Workpiece Material & Heterogeneous & Homogeneous \\
\hline Cutting Physics & Atomic Cluster Model & Shear Plane Model \\
\hline Energy Consideration & $\begin{array}{l}\text { Interatomic Potential } \\
\text { Functional }\end{array}$ & Shear/Friction Power \\
\hline Cutting Force & Interatomic Forces & Plastic Deformation \\
\hline Chip Formation & $\begin{array}{l}\text { Inner Crystal Deformation } \\
\text { (Point Defects or Dislocation) }\end{array}$ & $\begin{array}{l}\text { Inter Crystal } \\
\text { Deformation } \\
\text { (Grain Boundary Void) }\end{array}$ \\
\hline Deformation and Stress & Discontinuous & Continuous \\
\hline Cutting Tool Edge Radius & Significant & Ignored \\
\hline Cutting Tool Wear & Cutting Face and Cutting Edge & Rake Face \\
\hline
\end{tabular}

Table 2. Comparison of Nanometric Cutting and Conventional Cutting Mechanics (Adapted from Luo et al., 2003)

\section{The simulation set-up and procedure}

There are many issues to address for the MD simulation set-up, namely; the software and the hardware. For the hardware, suitable computer system configuration should be utilized depending on whether serial or parallel processing is required. For the software, there are many open source MD simulation software that are available. Two of the most popular software are DLPOLY and LAMMPS. (Another option is to develop one's own MD software from the scratch.) There are also open source software for the visualization of the simulation like the VMD. A typical structure can be seen in Figure 3, which comprises the preprocessing, the main MD processing and the post-processing parts.

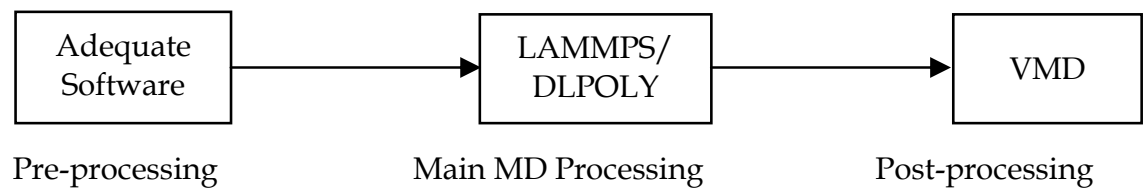

Fig. 3. Software Methodology Flowchart

\subsection{Pre-processing}

A suitable software has to be used to set-up the simulation model. A way to do this is to place the atoms on a perfect crystal lattice structure that represents the atomic structure of the material to be studied. The positions of atoms from an earlier simulation can also be used to initialize a new simulation (Cheong et al., 2001). 


\subsection{MD processing}

The main MD software accepts the input data of the atomic configuration and then integrates the equation of motion for the interacting atoms.

\section{LAMMPS-Large-Scale Atomic/Molecular Massively Parallel Simulator}

This is a classical MD software that models an ensemble of atoms using a variety of empirical potentials and boundary conditions. It runs on single and parallel processor computers. It is an open-source code and it is distributed under the terms of the GNU public licence. The LAMMPS computes the Newton's equation of motion for a system of interacting atoms. It requires as its input; the types of atoms and the list of their initial coordinates, molecular topology information and the empirical potentials assigned to all the atoms.

\section{DL_POLY}

This is a general purpose MD software for the simulation of a wide range of atomic and molecular systems. It affords the use of standard and user defined interatomic potentials for the selected system. It also accommodates many boundary conditions, namely; cubic periodic, slab, orthorhombic periodic, parallelepiped periodic etc. (Smith \& Todorov, 2005).

\subsection{Post-processing}

\section{VMD - Visual molecular dynamics}

The VMD is a molecular visualization software for displaying and analyzing atomic systems by using 3-D graphics technology. The VMD can be employed for the visual display of the LAMMPS/DL_POLY MD simulation results.

\subsection{The simulation configuration}

Various configurations are used for the simulation of nanoscale machining, to optimize computational resources. All the configuration share the same features in that they consist of the workpiece and the tool. Generally, the workpiece can be divided into boundary, Newtonian and thermostat atoms (See Figure 4).

\begin{tabular}{|c|c|}
\hline Parameters & Values \\
\hline Bulk Temperature & $293 \mathrm{~K}$ \\
\hline Cutting Direction & [100]-Along the -axis \\
\hline Cutting Speed & $150 \mathrm{~m} / \mathrm{s}$ \\
\hline Cutting Depth & $1.0 \mathrm{~nm}$ \\
\hline Time Step & $0.3 \mathrm{fs}$ \\
\hline Run & 100000 steps \\
\hline
\end{tabular}

Table 3. A Typical MD Simulation Parameters 


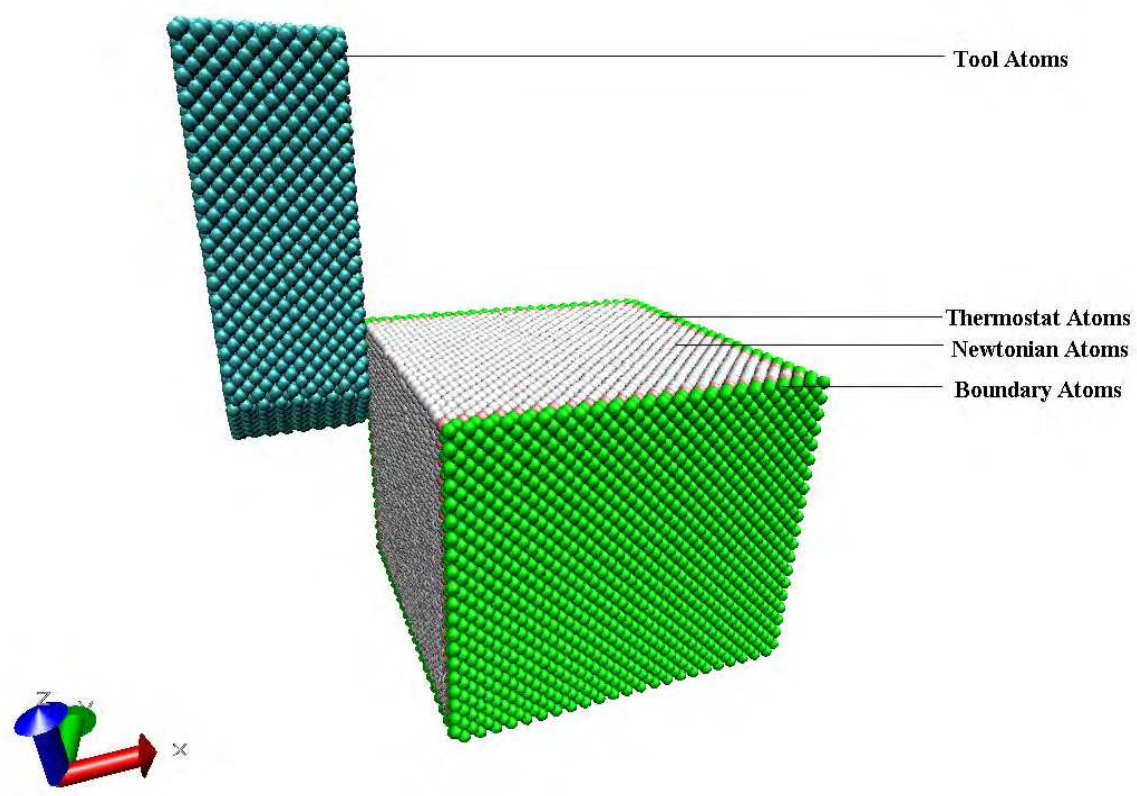

Fig. 4. A Simulation Model

Table 3 shows the simulation conditions that can be applied in a study. The workpiece is crystalline copper and the tool is also crystalline diamond. The configuration has a total of 54232 atoms. The workpiece consists of 43240 copper atoms with FCC lattice It includes 3 kinds of atoms namely; boundary atoms, thermostat atoms and Newtonian atoms. The boundary atoms are kept fixed to reduce edge effects. The thermostat atoms conduct the heat generated during the cutting process out of the cutting region. This is achieved by the velocity scaling of the thermostat atoms, (with the conversion between the kinetic energy (KE) and temperature) via equation (26),

$$
\sum_{i} \frac{1}{2} m_{i} v_{i}^{2}=\frac{3}{2} N k_{B} T_{i}
$$

Where $m_{i}$ is the mass of the ith atom, $v_{i}$ is the resultant velocity of the ith atom, $N$ is the number of the thermostat atoms, $T_{i}$ is the temperature of the ith atom and $k_{B}$ is the Boltzmann constant $\left(1.3806504 \times 10^{-23} \mathrm{JK}^{-1}\right)$

Whenever the temperature of the thermostat atoms exceeds the preset bulk temperature of $293 \mathrm{~K}$, their velocities are scaled by using equation (27),

$$
v_{i, \text { new }}=v_{i} \sqrt{\frac{T_{\text {desired }}}{T_{\text {current }}}}
$$

Where $T_{\text {current }}$ is the current temperature that is calculated from the $\mathrm{KE}$ and the $T_{\text {desired }}$ is the desired temperature. 
The Newtonian atoms obey the Newton's equation of motion. The cutting tool consists of 10992 carbon atoms with diamond lattice structure. In this case, the cutting tool is pointed shaped and it can be modelled as a rigid or as a non-rigid body.

The atomic interactions in the simulation are the following, namely;

$\mathrm{Cu}-\mathrm{Cu}$ : interactions between copper atoms

$\mathrm{Cu}-\mathrm{C}$ : interactions between copper atoms and diamond atoms

$\mathrm{C}-\mathrm{C}$ : interactions between the diamond atoms

Suitable interatomic potentials are required for all the above atomic interactions.

\section{Some examples of MD simulation of nanomachining}

Belak and Stowers pioneered work on the MD simulation of nanometric machining (See Figure 5). Copper was used as the workpiece with $10^{3}-10^{6}$ atoms at room temperature. The simulations were in 2D and the focus was on the chip formation process, mechanisms of plastic deformation, flow of material and the flow of energy into the chip and workpiece. They modelled the workpiece by using the EAM potential and they used a shifted and truncated LJ potential for the tool-workpiece interface. Shimada et al 1992 also carried out MD machining simulations using copper as the workpiece (Figure 6). They used the Morse potential for the atomic interactions and showed the chip formation for the simulation model of 6076 atoms at the cutting speed of $200 \mathrm{~m} / \mathrm{s}$.

(Rentsch \& Inasaki, 1994) modelled a copper work material and a diamond tool for their study. They used the Lennard-Jones potential function for the copper atom interactions, but kept the boundaries and the tool stiff. A total of 11476 atoms in 13 horizontal $(1,1,1)-$ layers of fcc-lattice were used for the copper, and the tool was shaped from a diamond lattice block by clearing on the four $(1,1,1)$-planes. Using a cutting speed of $100 \mathrm{~m} / \mathrm{s}$, they observed a pronounced build-up phenomenon after 25000 time steps (see Figure 7).

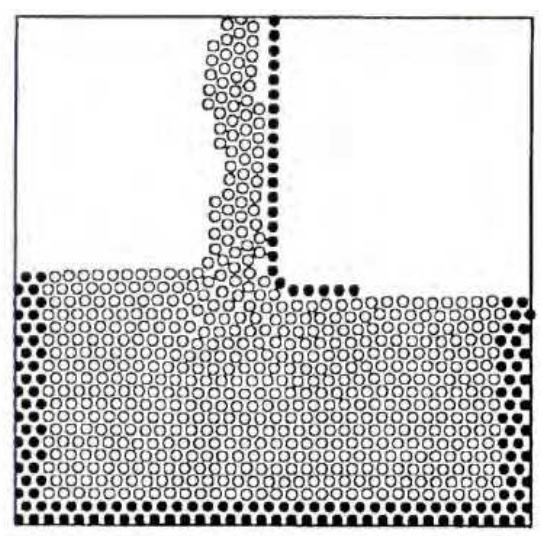

(a)

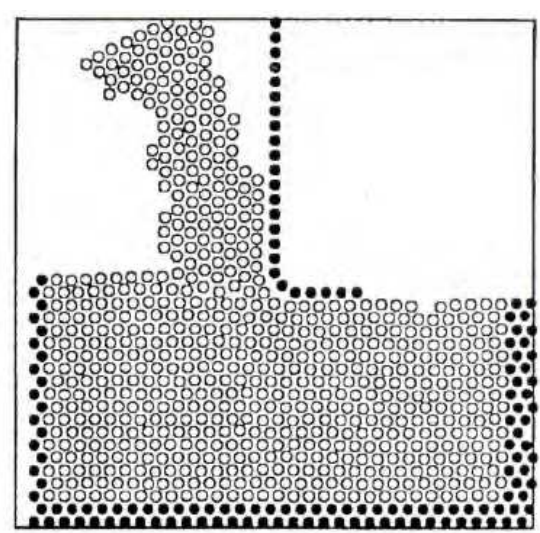

(b)

Fig. 5. MD Simulation of the Orthogonal Cutting of Copper; (a) with cutting speed of $2500 \mathrm{~m} / \mathrm{s}$ and (b) with cutting speed of $500 \mathrm{~m} / \mathrm{s}$ (Belak \& Stowers, 1990) 


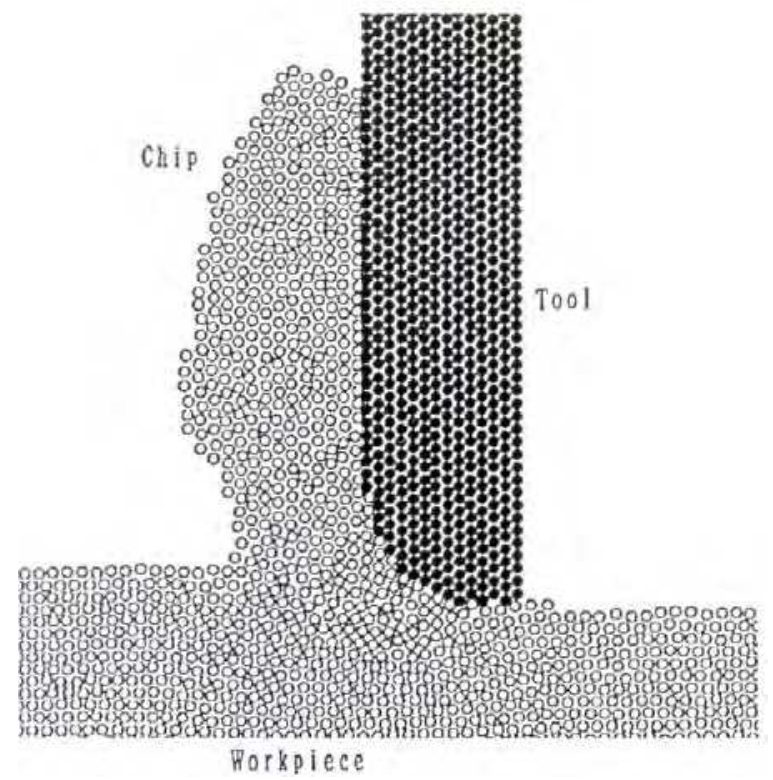

Fig. 6. MD Simulation of Cutting of Copper (Shimada et al., 1992)

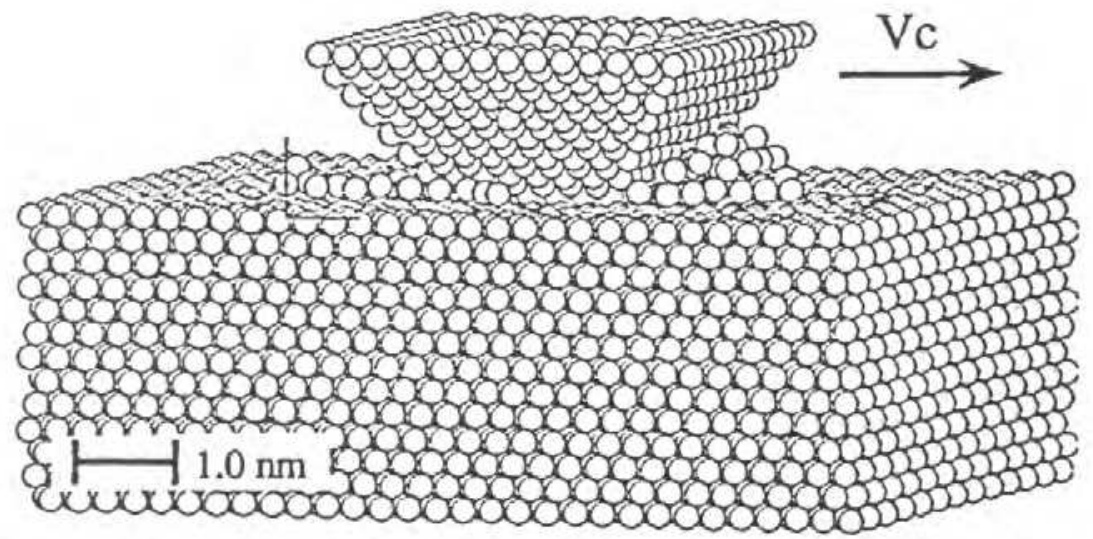

Fig. 7. Advanced MD Simulation with Straight Aligned Tool (Rentsch \& Inasaki, 1994)

The MD simulation of nanometric cutting was carried out by Komanduri team with a range of negative-rake tools to simulate the Ultra-Precision Grinding (UPG) process (Komanduri et al., 1999). A copper work material and an infinitely hard tool (tungsten) were used in the simulations. A pairwise sum of Morse potential was used for the study, in which they concluded that simulation tests can facilitate a better understanding of the process without the need for expensive and time consuming machining or grinding experimental work. 
The investigation of the fundamental atomistic processes in chemical mechanical polishing of copper was carried out by Ye et al (2002). They simulated the nanoscale polishing of a copper surface by a single abrasive particle, using the embedded-atom potential. The temperature was controlled by maintaining $1.2 \mathrm{~nm}$ of the substrate at $300 \mathrm{~K}$ and the rescaling of atom velocities was performed whenever the temperature deviated more than $10 \mathrm{~K}$ from the specified value. This allowed the transfer of heat from the machined region to the bulk of the work-material. They focused on the mechanical abrasion aspect of material removal and found that dislocations and atomically rough planarized surface were formed. They also studied the nature of the material removal, chip formation, materials defects and frictional forces as functions of the cutting speed, depth of cut and abrasive geometry. They established that the material removal rate scales linearly with the depth of planarization and is directly proportional to the velocity of cut.

To be more realistic, (Rentsch \& Inasaki, 2006) extended the MD material modelling to consider fluids, like coolants. They considered the impact of such fluids on the surface generation and the tribological contact conditions. The fluid-fluid interactions were calculated on the basis of the Lennard-Jones potential function and the embedded-atom potential function was used for the inner workpiece reactions (the internal tool dynamics were ignored). They observed an intensive self-diffusion of the fluid atoms, and these filled the whole free space above the workpiece. No impact on the stress distribution was observed, but the whole fluid-tool/workpiece contact was heated up in a narrow range (See Figures 8 (a) and (b).

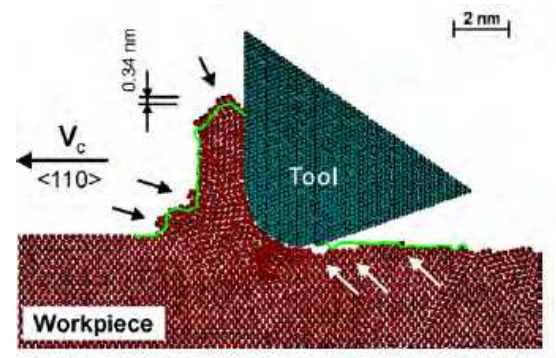

(a)

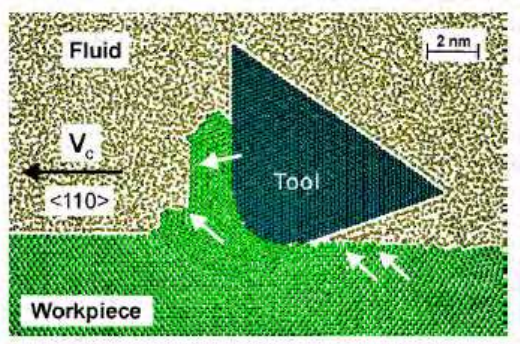

(b)

Fig. 8. MD Machining Simulation (a) without fluid (vacuum) after 230.7ps (b) with fluid after 230ps , (Rentsch \& Inasaki, 2006) 
Shimizu et al (2006) carried out MD simulations on the effect of vibration, velocity and acceleration in vibration assisted cutting. They used aluminium as the workpiece and diamond as the tool. Using Morse potentials for the interactions, they obtained that the effect of vibration on the plastic flow and cutting forces is more than the effect due to acceleration. See some snapshots of the simulation in Figure 9.

To extend the capability of MD studies, Pei et al., (2009), performed large scale MD simulations with model size of up to 10million atoms (Figures 10 (a), (b) and (c). Their results showed that as the cutting depth decreases, the tangential cutting force decreases and that size effects exists in nanometric cutting.

Oluwajobi \& Chen, (2010a, 2011a, 2010b, 2011b, 2012) have conducted several MD simulations of nanometric machining. To show the effect of interatomic potentials on nanomachining, three popular potentials namely; EAM, Morse and the Lennand-Jones, were employed to model nanometric machining. The following shows the results;

Modelling with LJ Potential

The LJ parameters used for the atomic interactions are $\sigma=2.2277$ Angstroms and $\varepsilon=0.415 \mathrm{eV}$ (Hwang et al 2004), which apply to both the $\mathrm{Cu}-\mathrm{Cu}$ and the $\mathrm{Cu}-\mathrm{C}$ interactions. The cutting forces are shown in Figure 11.

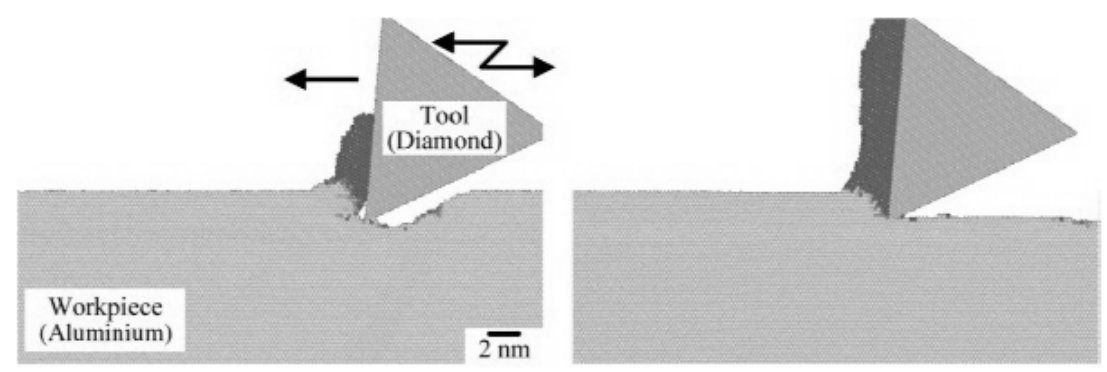

(a) $t=145 \mathrm{ps}$

(b) $t=330 \mathrm{ps}$

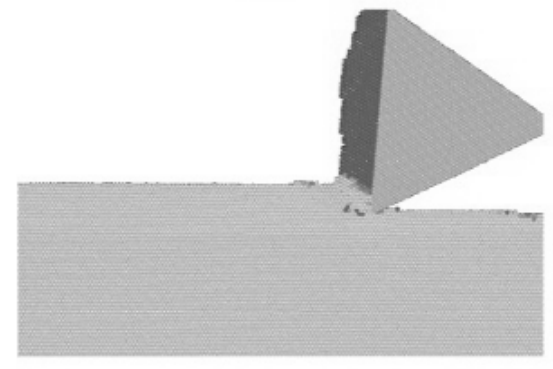

(c) $t=415 \mathrm{ps}$

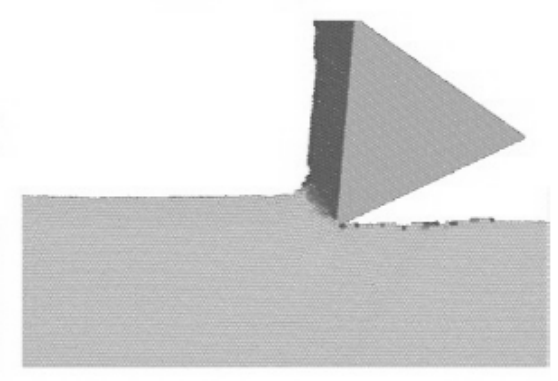

(d) $t=500 \mathrm{ps}$

Fig. 9. Snapshots of Atomic Arrays in Vibration-assisted Cutting Process and Travelling Distance from Initial Arrays. Cutting speed, $V_{c}=50 \mathrm{~m} / \mathrm{s}$, Amplitude, A=4nm and Frequency, $\mathrm{f}=4 \mathrm{GHz}$ (Shimizu et al., 2006). 

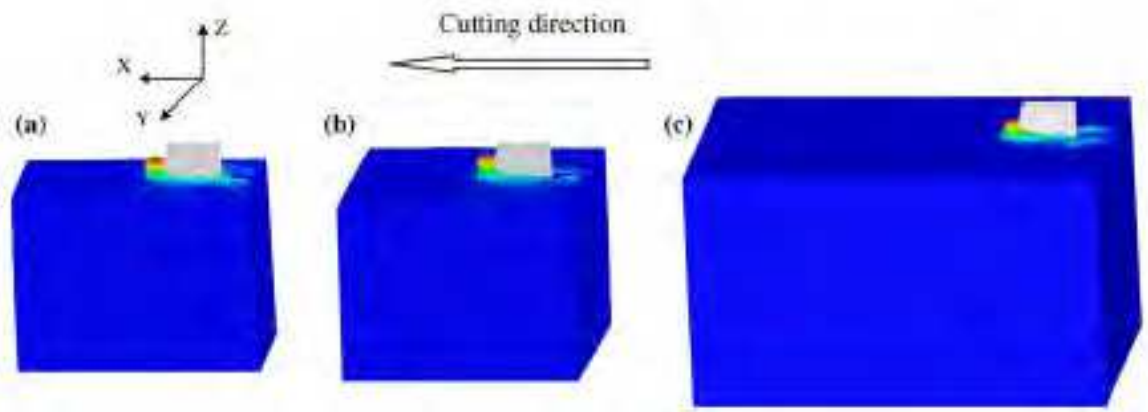

Fig. 10. MD Simulation Models with Number of the Atoms in the Workpiece around (a) 2 Million, (b) 4 Million and (c) 10 Million (Pei et al., 2009)

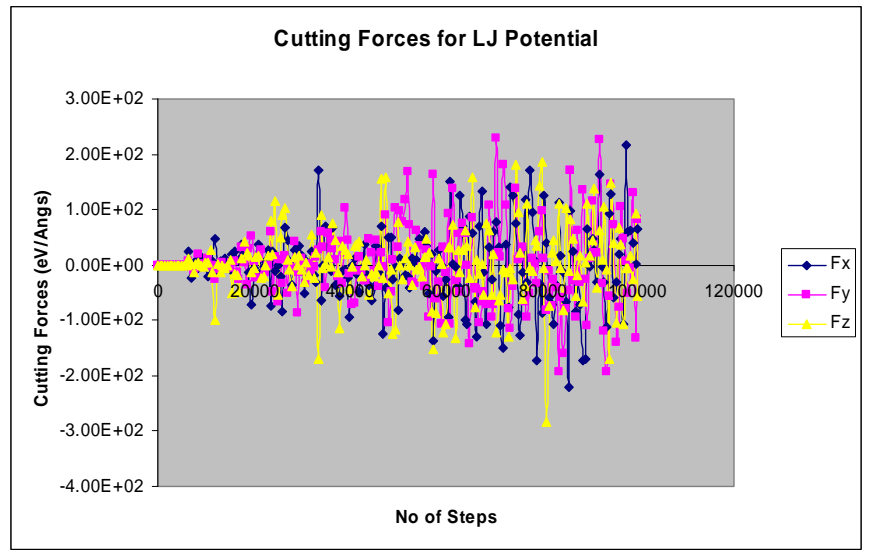

Fig. 11. Cutting Forces for LJ Potential (Oluwajobi \& Chen, 2011a)

Modelling with Morse Potential

For Cu-Cu interactions: (Girifalco \& Weizer, 1959, Pei et al., 2006)

$D=0.3429 \mathrm{eV}, \alpha=0.13588(\mathrm{~nm})^{-1}, r_{e}=0.2866 \mathrm{~nm}$

For Cu-C interactions: (Hwang et al., 2004)

$D=0.087 \mathrm{eV}, \alpha=0.17(\mathrm{~nm})^{-1}, r_{e}=0.22 \mathrm{~nm}$

The cut-off distance chosen was 6.4 Angstroms (that is, the interactions between atoms separated by more than this distance are neglected). The cutting forces are shown in Figure 12.

Modelling with EAM Potential

For the EAM potential, parameters used can be found in (Oluwajobi \& Chen 2011a) and the cutting forces are shown in Figure 13. 


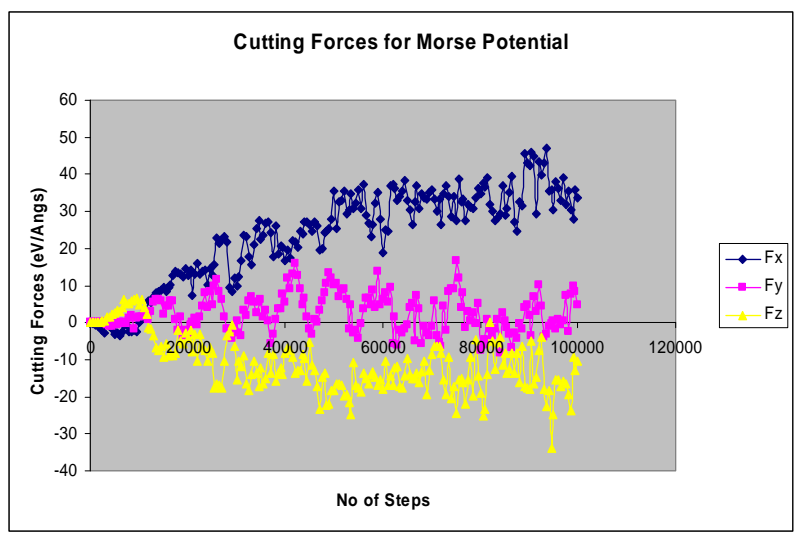

Fig. 12. Cutting Forces for Morse Potential (Oluwajobi \& Chen, 2011a)

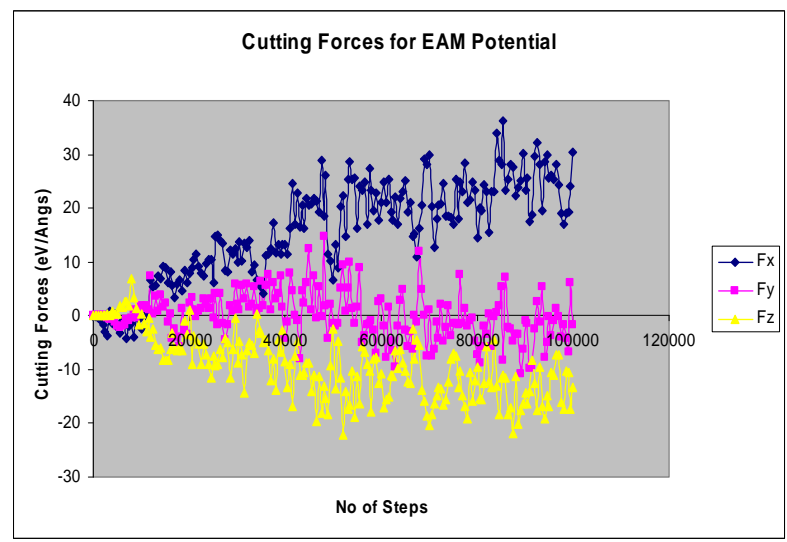

Fig. 13. Cutting Forces for EAM Potential (Oluwajobi \& Chen, 2011a)

From Figures 11 - 13, it can be observed that the cutting forces variation is lowest for the EAM potential. The results of the EAM model are comparable with those of (Pei et al., 2006, Promyoo et al., 2008), and the EAM potential best describes the metallic bonding in the copper atoms. In contrast, the pair potentials (both LJ and Morse potentials), do not incorporate the many-body effects; they have no environmental dependence and they do not account for the directional nature of bonding in metals (Li et al., 2008). Through this investigation, it was identified that the EAM potential is the most appropriate of the 3 potentials commonly used for the modelling of nanomachining of copper with diamond tool. This is because the EAM potential provides the best description of the metallic bonding in the workpiece, also, the cutting forces variation is smallest; the potential and total energies are most stable for the depth of cut considered. The study recommended that the EAM potential should be used, rather than LJ and Morse potentials for the modelling of copper and other fcc metals in MD simulations of nanomachining (Oluwajobi \& Chen, 2011a). 

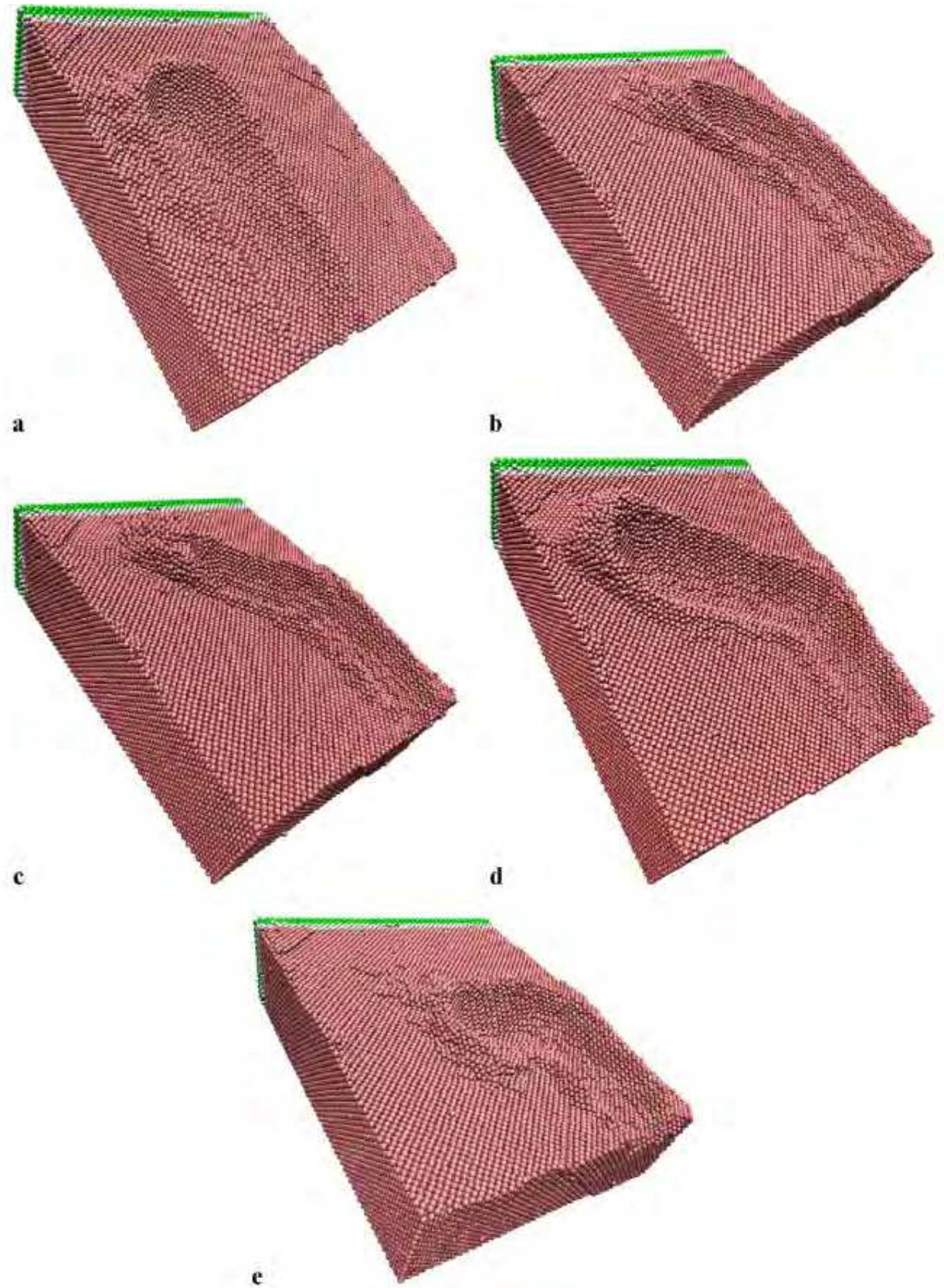

Fig. 14. Groove Profiles for Different Cutting Directions (a) 0deg (b) 30deg (c) 45deg (d) 60deg (e) 90deg (Zhang et al., 2009) 
Many existing MD simulation studies on nanometric cutting have been limited to single pass or simple line-type groove. As an extension of the single pass studies, Zhang et al., (2009) modelled folder- line grooves for AFM-based nanometric cutting process of copper workpiece with diamond tool (Figure 14). They used the EAM potential for the coppercopper interactions and the Morse potential for the copper-diamond interactions. They treated the diamond tool as rigid and concluded that the normal, lateral and the resultant forces were almost symmetric with respect to the critical folder angle of $45^{\circ}$. Shi et al., (2011) investigated the multi-groove simulation of single-point tuning of copper workpiece with diamond tool. They used two diamond tools, offset by a fixed distance to simulate a two-groove cutting and modelled the copper-copper and the copper-diamond interactions by using the Morse potential (Figure 15). They also treated the tool as a rigid body and observed that the tool forces increase with increase in feed rate and depth of cut. In practice, most machining processes involve the use of multiple passes to create new surface patterns and the diamond tool is deformable and subjected to wear. To address the above problem, novel multi-pass nanometric machining MD simulations have been carried out, which show the consecutive passes of cut. See Figures 16 and 17 (Oluwajobi \& Chen, 2011b).

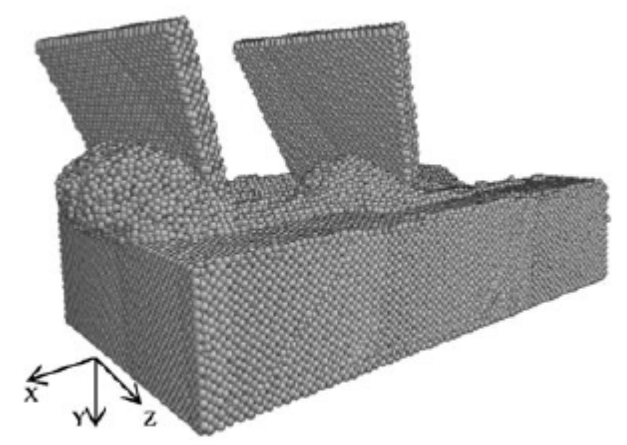

(a)

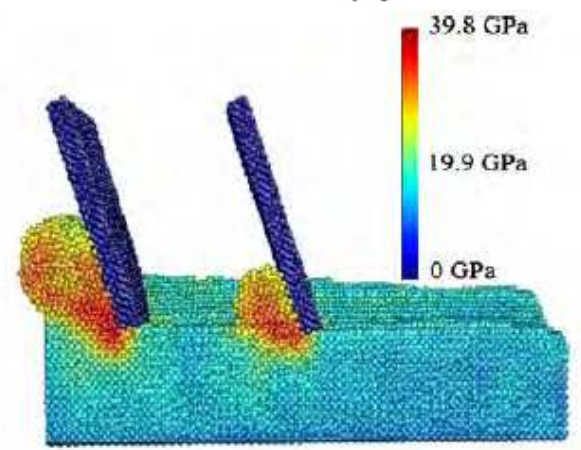

(b)

Fig. 15. MD Simulation of Multi-groove Cutting with Two Diamond Tools: (a) 3D perspective view (b) Stress Distribution (Shi et al., 2011) 

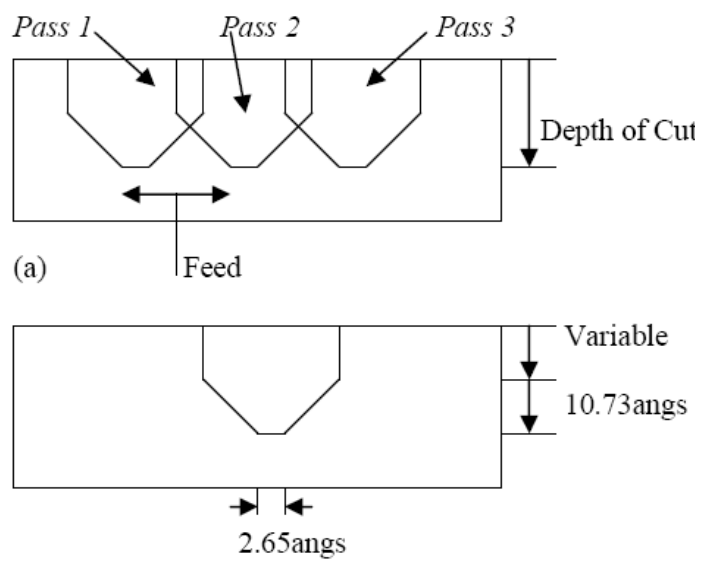

(b)

Fig. 16. a. Cross Section of the Machined Grooves with Passes 1-3 (direction of cut is perpendicular to the paper face) 16b: Tool Tip Dimensions (Oluwajobi \& Chen, 2011b)

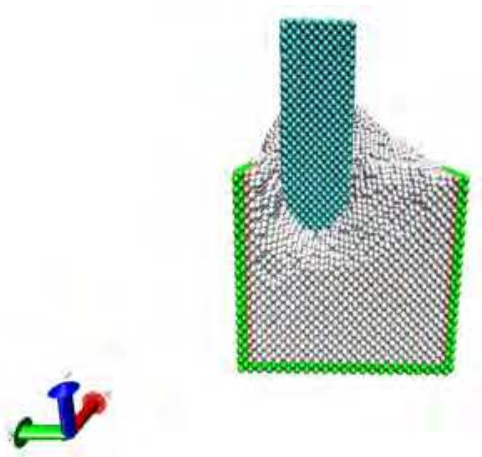

(a)

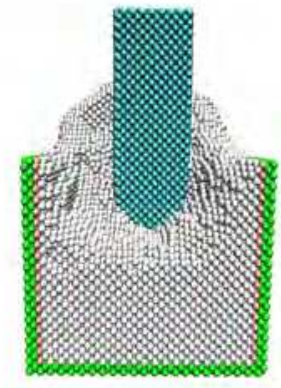

(b)

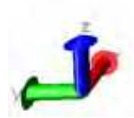

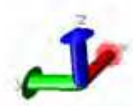

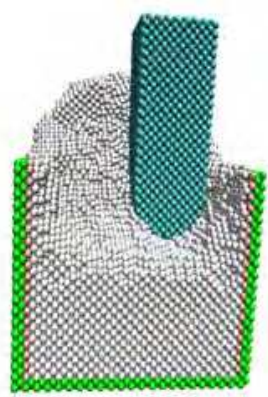

(c)

Fig. 17. MD Simulation of Multipass Nanometric Machining (a) pass 1 (b) pass 2 (c) pass 3 (Oluwajobi \& Chen, 2011b) 
From the simulations, it was observed that the magnitude of the tangential and the normal cutting force components increase with the increase in the depth of cut and they decrease with the consecutive passes. Also, the lateral force components are influenced by atomic vibrations and the cutting cross sectional area (Oluwajobi \& Chen, 2011b, 2012).

\section{Conclusions}

The MD simulation of nanoscale machining has come a long way from inception; from the use of 'primitive' two dimensional systems to two and a half dimensional system and now to 'realistic' three dimensional systems. More developments have occurred from the first simulations where not many or no quantitative analyses were carried out, to now, where rigorous quantitative analyses for the evaluation of the machine process parameters are the norm. Also, the overall configuration have increased from a few thousands to millions atoms at present. The commonly used potentials for MD simulations of metals include LJ, Morse, EAM and MEAM. In many cases, the rationale or justification for their use are not given except for the reference to their use in earlier studies. Ideally, multi-body potentials (EAM and MEAM) should be used for metals, rather than pairwise potentials (LJ and Morse); because they more correctly model the metallic bonding. It is important to use appropriate interatomic potentials for MD simulations so as to obtain useful results. It is now feasible to carry out multipass nanometric machining MD simulations. From the results of such simulations, minimum surface roughness can be effectively evaluated, which is very critical in the industry.

At present, MD methods can only handle small length and time scales. This is far from what obtains during experimental studies. To tackle these problems, multiscale methods are been used. Spatial and temporal multiscale techniques would considerably extend the length and time scales in simulations respectively (Medyanik, 2007, Medyanik \& Liu, 2008).

\section{Nomenclature}

$\begin{array}{ll}a_{i} & \text { Acceleration of atom } i, \frac{d^{2} r_{i}}{d t^{2}} \\ a_{i j} & \text { Function that limit the range of interaction in Tersoff's potential } \\ A & \text { Material dependent constant } \\ b & \text { Third derivative of position, } \frac{d^{3} r}{d t^{3}} \\ b_{i j} & \text { A parameter that provides information for the direction and the length of bond } \\ & \text { (Bond strength) } \\ c & \text { Fourth derivative of position, } \frac{d^{4} r}{d t^{4}} \\ D & \text { Material dependent constant } \\ E & \text { Elementary Charge } \\ E_{t o t} & \text { Energy of interacting particles } \\ f & \text { Total embedding energy }\end{array}$


$f_{A}$

$f_{C}$

$f_{R}$

$F_{i}$

$\mathrm{F}_{\mathrm{wi}}$

$\mathrm{F}_{\mathrm{ti}}$

$\mathrm{F}_{\text {wtij }}$

$\mathrm{F}_{\mathrm{wwij}}$

$\mathrm{F}_{\text {twij }}$

$\mathrm{F}_{\mathrm{ttij}}$

$G_{i}$

$G^{\prime}$

$G^{\prime \prime}$

h

$\hbar$

$m_{i}$

$M_{1}, M_{2}$

N

$N_{e}$

$\mathrm{N}_{\mathrm{t}}$

$\mathrm{N}_{\mathrm{w}}$

$r$

$r_{e}$

$r_{i}$

$r_{i j}$

$r_{o}$

$t$

R

$\mathrm{r}_{\mathrm{wi}}$

$\mathrm{r}_{\mathrm{ti}}$

$r_{w t i j}$

$r_{w w i j}$
Attractive pair potential associated with bonding

A smooth cut-off function to limit the range of the potential

Repulsive pair potential

Force acting on atom $i$

The force acting on the $i$-th workpiece atom

The force acting on the $i$-th cutting tool atom

The interatomic forces acting on the $i$-th workpiece atom from the cutting tool atom $j$

The interatomic forces acting on the $i$-th workpiece atom from the workpiece atom $j$

The interatomic forces acting on the $i$-th cutting tool atom from the workpiece atom $j$

The interatomic forces acting on the $i$-th cutting tool atom from the cutting tool atom $j$

Material dependent constant

Embedding energy for placing atom $i$ into the electron density

First derivative of the embedding energy

Second derivative of the embedding energy

Planck constant $\left(6.626069 \times 10^{-34} \mathrm{~J} \mathrm{~s}\right)$

Reduced Planck constant $\frac{h}{2 \pi}\left(1.054571 \times 10^{-34} \mathrm{~ms}^{2} \mathrm{~kg} / \mathrm{s}\right)$

Mass of atom i

Nuclear Masses

Number of atoms

Number of electrons

Number of cutting tool atoms

Number of workpiece atoms

Distance between atoms

Equilibrium distance between atoms $i$ and $j$

Position of atom or particle $i$

Instantaneous distance between particles $i$ and $j$

Material dependent constant

Time

Material dependent constant

The displacement vector of the $i$-th workpiece atom

The displacement vector of the $i$-th cutting tool atom

The displacement vector of the $i$-th workpiece atom and the interacting cutting tool atom $j$

The displacement vector of the $i$-th workpiece atom and the interacting workpiece atom $j$ 


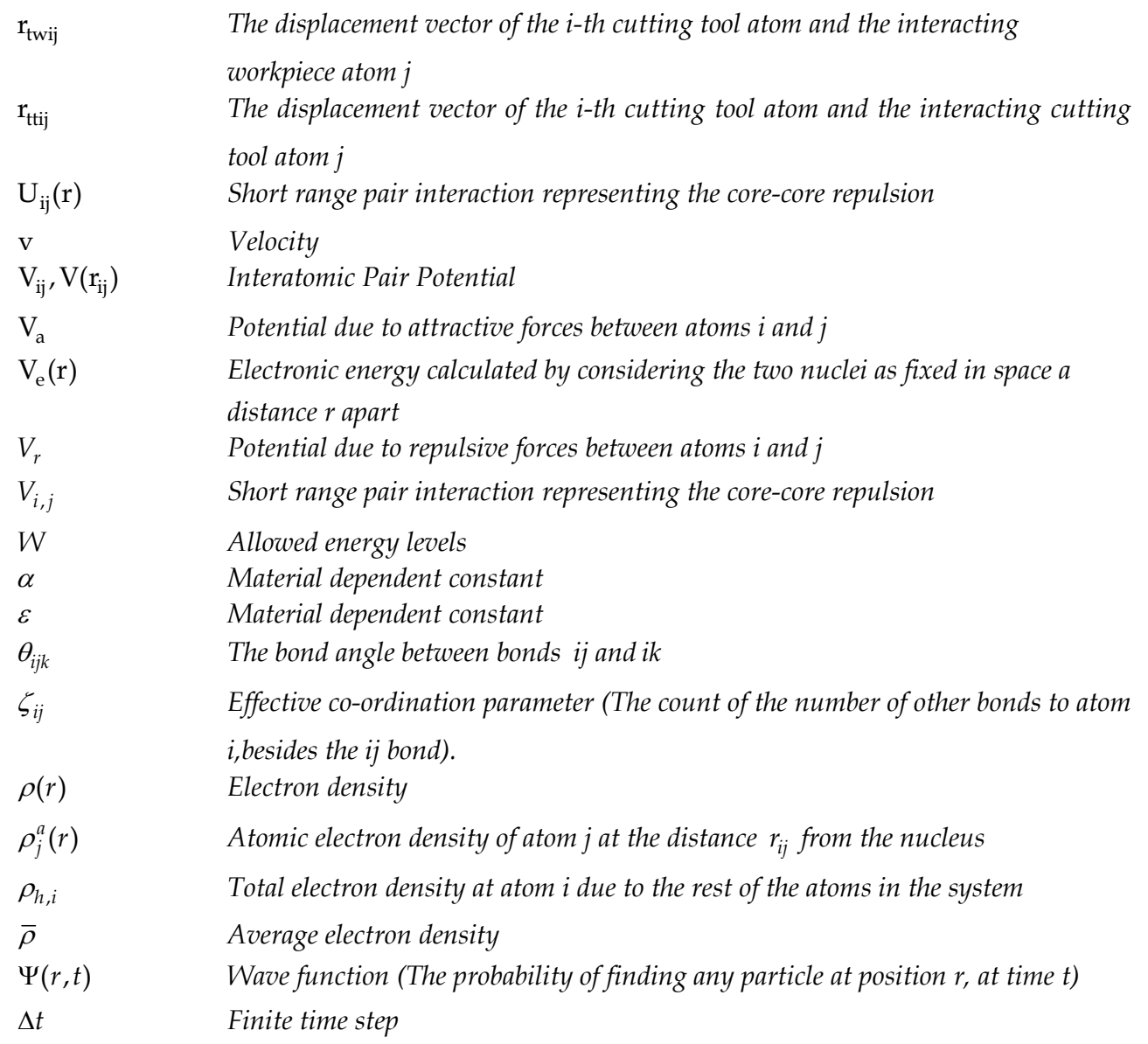

\section{References}

Alder B.J.and T.E. Wainwright (1957), Phase Transition for Hard Sphere System, Journal of Chemical Physics, Vol. 27, pp 1208-1209

Alder B.J.and T.E. Wainwright (1959), Studies in Molecular Dynamics. I. General Method, Journal of Chemical Physics, Vol. 31 pp 459-466

Allen M.P. and D.J. Tildesley (1988), Computer Simulation of Liquids, (Oxford University Press) Baskes M.I. (1992), Modified Embedded-Atom Potentials for Cubic Materials and Impurities, Physical Review B, Vol. 46, pp 2727-2742

Beeman D. (1976), Some Multistep Methods for use in Molecular Dynamics Calculations, Journal of Computational Physics Vol. 20 pp 130-139

Belak, J. and Stowers I. F. (1990), A Molecular Dynamics Model of the Orthogonal Cutting Process, Proceedings of the American Society of Precision Engineering, pp 7679. 
Belak, J. and Stowers I. F. (1991), The Indentation and Scratching of a Metal Surface: A Molecular Dynamics Study, Fundamentals of Friction: Macroscopic and Microscopic, Singer, Pollock E 220, pp 1-10

Born M. and J.E. Mayer (1932), Zur Gittertheorie de Ionenkristalle, Z. Physik, Vol. 75, pp 1

Chamati H., N. Papanicolau, Y. Mishin \& D.A. Papaconstantopoulos (2006), EmbeddedAtom Potential for Fe and its Application to Self-Diffusion on Fe(100), Surface Science, Vol. 600, pp 1793-1803

Cheng K., X. Luo, R. Ward \& R. Holt (2003), Modelling and Simulation of the Tool Wear in Nanometric Cutting, Wear, Vol. 255, pp 1427-1432

Cheong W.C.D, L. Zhang \& H. Tanaka (2001), Some Essentials of Simulating Nano-Surface Processes Using the Molecular Dynamics Method, Key Engineering Materials, Vol. 196, pp 31-42

Cox H., R.L. Johnston \& J.M. Murrel (1999), Empirical Potentials for Modelling Solids, Surfaces and Clusters, Journal of Solid State Chemistry, Vol. 145, pp 517540

Ducobu F., E. Filippi \& E. Rivière-Lorphèvre (2009), Chip Formation and Minimum Chip Thickness in Micro-milling, In Proceedings of the 12th CIRP Conference on Modelling of Machining Operations, pp 339-346.

Ercolessi F. (1997), A Molecular Dynamics Primer, Spring College in Computational Physics, ICTP, Trieste, June 1997, http://www.fisica.uniud.it/ ercolessi/md/md/ (Accessed in 2008)

Ercolessi F., E. Tosatti \& M. Parrinello (1986), Au (100) Surface Reconstruction, Physical Review Letters, Vol. 57, pp 719-722

Ercolessi F. and J.B. Adams (1994), Interatomic Potentials from First Principles Calculations: The Force-Matching Method, Europhysics Letters, Vol. 26, No. 8, pp 583-588

Field M.J. (1999), A Practical Introduction to the Simulation of Molecular Systems, Cambridge University Press Finnis M.W. and J.E. Sinclair (1984), A Simple Empirical N-Body Potential for Transition Metals, Philosophical Magazine A, Vol. 50, Iss. 1, pp $45-50$

Foiles S.M. (1985), Application of the Embedded Atom Method to Liquid Transition Metals, Physical Review B, Vol. 32, No 6, pp 3409-3415

Foiles S.M., M.I. Baskes \& M.S. Daw (1986), Emdedded-Atom-Method Functions for the FCC Metals Cu, Ag, Au, Ni, Pd, Pt, and their Alloys, Physical Review B, Vol. 33, No 12, pp 7983-7991

Frenkel D. and B. Smit (2001), Understanding Molecular Simulations: From Algorithms to Applications, Computational Science, Academic Press

Gear C.W. and K.W. Tu (1974), The Effect of Variable Mesh Size on the Stability of Multistep Methods, SIAM Journal of Numerical Analysis, Vol. 11, No 5, pp 10251043

Gear C.W. and D.S. Watanabe (1974), Stability and Convergence of Variable Order Multistep Methods, SIAM Journal of Numerical Analysis, Vol. 11, No 5, pp 1044-1058

Gibson J.B., A.N. Goland, M. Milgram \& G.H. Vineyard (1960), Dynamics of Radiation Damage, Physical Review, Vol. 120, Iss. 4, pp 1229-1253

Girifalco L.A. and V.G. Weizer (1959), Application of the Morse Potential Function to Cubic Metals, Physical Review, Vol. 114, pp 687-680

Haile J.M. (1997), Molecular Dynamics Simulation: Elementary Methods, Wiley-Interscience 
Hernandez E.R. (2008), Molecular Dynamics from Basic Techniques to Applications: A Molecular Dynamics Primer, Frontiers in Contemporary Physics, AIP Conference Proceedings, Vol. 1077, Iss.1, pp 95-123

Hwang H.J., O-K Kwon \& J. W. Kang (2004), Copper Nanocluster Diffusion in Carbon Nanotube, Solid State Communications, Vol. 129, pp 687-690

Ikawa N., S. Shimada, H. Tanaka \& G. Ohmori (1991), An Atomistic Analysis of Nanometric Chip Removal as Affected by Tool-Work Interaction in Diamond Turning, Annals of the CIRP, Vol. 40, Iss. 1, pp 551-554

Ikawa N., S. Shimada \& H. Tanaka (1992), Minimum Thickness of Cut in Micromachining, Nanotechnology Vol. 3, pp 6-9

Jackson M.J. (2008), Micro and Nanomachining, In J.P. Davin - Machining: Fundamentals and Recent Advances, pp 271-297, Springer

Kenny S.D., D. Mulliah, C.F. Sanz-Navarro \& R. Smith (2005), Molecular Dynamics Simulations of Nanoindentation and Nanotribology, Philosophical Transactions of the Royal Society A., Vol. 363, No 1833, pp 1949-1959

Khukhryansky Y. P., E.A. Shunikov and V.V. Emelyanov (2004), Study of Cluster Forming at Growth of A3B5 Semiconductor Compounds from Liquid Phase, Journal of Crystal Growth, Vol. 269, pp 292-297

Komanduri R., and L.M. Raff (2001), A Review on the Molecular Dynamics Simulation of Machining at the Atomic Scale, Proceedings of the Institution of Mechanical Engineers, Vol. 215, Part B, pp 1639-1672

Kragelsky I.V., Dobychin M.N., \& Kombalov V.S. (1982), Friction and Wear-Calculation Methods, Pergamon Press, New York

LAMMPS Manual, http:/ /lammps.sandia.gov/doc/Manual.pdf, (Accessed in 2009)

Leach A. (2001), Molecular Modelling: Principles and Applications, Prentice Hall

Lee B, B.D.Wirth, J. Shim, J. Kwon, S.C. Kwon \& J. Hong (2005), Modified EmbeddedAtom Method Interatomic Potential for the Fe-Cu Alloy System and Cascade Simulations on Pure Fe and Fe-Cu Alloys, Physical Review B, Vol. 71, pp 184205 (1-15)

Lennard-Jones J.E. (1924), On the Forces between Atoms and Ions, Proc. Royal Soc. Vol. 109, pp 584-597

Li J.H., X.D. Dai, S.H. Liang, K.P. Tai, Y. Kong \& B.X. Lin (2008), Interatomic Potentials of the Binary Transition Metal Systems and Some Applications in Materials Physics, Physics Reports, Vol. 455, pp 1-134

Luo X., K. Cheng, X. Guo \& R. Holt (2003), An Investigation on the Mechanics of Nanometric Cutting and the Development of its Test-bed, International Journal of Production Research, Vol.41, No.7, pp 1149-1165

Luo X. (2004), 'High Precision Surfaces Generation: Modelling, Simulation and Machining Verification', PhD Thesis, Leeds Metropolitan University

Medyanik S.N. (2007), Atomistic Simulation Methods and Multiscale Modelling, Accessed October 2011 http:/ / multiscale.emsl.pnl.gov/docs/atomistic.pdf

Medyanik S.N. and W.K. Liu (2008), Multiple Time Scale Method for Atomistic Simulations, Computational Mechanics, Vol. 42, pp 569-577

Morse P.M. (1929), Diatomic Molecules according to Wave Mechanics II Vibrational Levels, Physical Review, Vol. 34, pp 57-64

Murrel J.N. and R.E. Mottram (1990), Potential Energy Functions for Atomic Solids, Molecular Physics, Vol. 69, pp 571-588 
Oluwajobi A.O. and X. Chen (2010a), The Fundamentals of Modelling Abrasive Machining Using Molecular Dynamics, International Journal of Abrasive Technology, Vol. 3, No 4, pp. 354-381

Oluwajobi A.O. and X. Chen (2010b), On Minimum Depth Cut in Nanomachining, In: Advances in Manufacturing Technology: Durham University and Glasgow Caledonian University, Proceedings of the $8^{\text {th }}$ International Conference on Manufacturing Research, University of Durham, Durham, pp 174-179

Oluwajobi A.O. and X.Chen (2011a), The Effect of Interatomic Potentials on the Molecular Dynamics Simulation of Nanometric Machining, International Journal of Automation and Computing, Vol. 8, No. 3, pp 326-332

Oluwajobi A.O. and X.Chen (2011b), The Effect of Depth of Cut on the Molecular Dynamics (MD) Simulation of Multi-Pass Nanometric Machining, Proceedings of the $17^{\text {th }}$ International Conference on Automation \& Computing, University of Huddersfield, Huddersfield, Sept. 2011, pp 40-45

Oluwajobi A. and X. Chen (2012), Multi-Pass Nanometric Machining Simulation Using the Molecular Dynamics (MD), Key Engineering Materials, Vol. 496, pp 241-246

Pei Q.X., C. Lu, F.Z. Fang \& H. Wu (2006), Nanometric Cutting of Copper: A Molecular Dynamics Study, Computational. Material Science, Vol. 37, pp 434-441

Pei Q.X., C. Lu, H.P. Lee \& Y.W. Zhang (2009), Study of Materials Deformation in Nanometric Cutting by Large-Scale Molecular Dynamics Simulation, Nanoscale Reseaech Letters, Vol. 4, pp 444-451

Plimpton S. J., (1995), Fast Parallel Algorithms for Short-Range Molecular Dynamics, Journal of Computational Physics, Vol. 117, pp 1-19 and www.lammps.sandia.gov

Potirniche G. P., M.F. Horstemeyer, G.J. Wagner \& P.M. Gullett (2006), A Molecular Dynamics Study of Void Growth and Coalescence in Single Crystal Nickel, International Journal of Plasticity, Vol. 22, pp 257-278

Promyoo R. H. El-Mounayri and X. Yang (2008), Molecular Dynamics Simulation of Nanometric Machining under Realistic Cutting Conditions, ASME International Conference on Manufacturing Science and Engineering (MSEC2008), October 7-10, 2008, Evanston, IL.

Rafii-Tabar H. and A.P. Sutton (1991), Long Range Finnis-Sinclair Potentials for FCC Metallic Alloys, Philosophical Magazine Letters, Vol. 63, pp 217-224

Rahman A. (1964), Correlations in the Motions of Atoms in Liquid Argon, Physical Review A, Vol.136, pp 405-411

Rapaport D.C. (2004), The Art of Molecular Dynamics Simulation, Cambridge University Press

Rentsch R. and I. Inasaki (1994), Molecular Dynamics Simulation for Abrasive Processes, Annals of the CIRP, Vol. 43, No 1, pp 327-330

Rentsch R. and I. Inasaki (2006), Effects of Fluids on the Surface Generation in Material Removal Processes, Annals of the CIRP, Vol. 55, No. 1, pp 1-4

Rentsch R. (2008), Nanoscale Cutting, in Nano and Micromachining, edited by Davin .J.P. and M.J. Jackson, Wiley-ISTE, pp 1-24

Schlick T. (2002), Molecular Modelling and Simulations: An Interdisciplinary Guide, Springer

Shi J., Y. Shi and C.R. Liu, Evaluation of a Three-Dimensional Single-Point Turning at Atomistic Level by a Molecular Dynamics Simulation, International Journal of Advanced Manufacturing Technology, Vol. 45, No. 1-4, 2011, pp 161-171

Shimada S., N. Ikawa, G. Ohmori, H. Tanaka, \& U. Uchikoshi (1992), Molecular Dynamics Analysis as Compared with Experimental Results of Micromachining, Annals of the CIRP Vol. 41, No 1, pp 117-120 
Shimada S., N. Ikawa, H. Tanaka, G. Ohmori and J. Uchikoshi (1993), Feasibility Study on Ultimate Accuracy in Microcutting using Molecular Dynamics Simulation, Annals of the CIRP, Vol. 42, No.1, pp 91-94

Shimizu J. H. Eda, M. Yoritsune and E. Ohmura (1998), Molecular Dynamics Simulations of Friction on the Atomic Scale, Nanotechnology, Vol. 9, pp 118-123

Shimizu J., L. Zhou \& H. Eda (2006), Molecular Dynamics Simulation of Vibration-Assisted Cutting: Influences of Vibration, Acceleration and Velocity, International Journal of Nanomanufacturing, Vol. 1, No. 1, pp 105-116

Smith R., D. Christopher \& S. Kenny (2003), Defect Generation and Pileup of Atoms during Nanoindentation of Fe Single Crystals, Physical Review B, Vol. 67, pp 24540510

Smith W. and I.T. Todorov (2005), The DL_POLY Molecular Dynamics Package,Z. Kristallogra, Vol. 220, pp 563-566

Stillinger F.H. and A. Rahman (1974), Improved Simulation of Liquid Water by Molecular Dynamics, Journal of Chemical Physics, Vol. 60, pp 1545-1557

Stillinger F.H. and T.A. Weber (1985), Computer Simulation of Local Order in Condensed Phases of Silicon, Physical Review B, Vol. 31, pp 5262-5271

Sutton A.P. and J. Chen (1990), Long-Range Finnis Sinclair Potentials, Philosophical Magazine Letters, Vol. 61, Iss. 3, pp 139-146

Tersoff J. (1988a), New Empirical Approach for the Structure and Energy of Covalent Systems, Physical Review B, Vol. 37 No 12, pp 6991-7000

Tersoff J. (1988b), Empirical Interatomic Potential for Silicon with Improved Elastic Properties, Physical Review B, Vol. 38 No 14, pp 9902-9905

Tuckerman M.E. and G.L. Martyna (2000), Understanding Modern Molecular Dynamics: Techniques and Applications, Journal of Physical Chemistry, Vol. 104, pp 159178

Van Gunsteren W. F. and H.J.C. Berendsen (1990), Computer Simulation of Molecular Dynamics: Methodology, Applications, and Perspectives in Chemistry, Anew. Chem. Int. Ed. Engl., Vol. 29, pp 992-1023

Verlet L. (1967), Computer Experiments on Classical Fluids I. Thermodynamics Properties of Lennard-Jones Molecules, Physical Review D, Vol.159, pp 98-103

Visual Molecular Dynamics (VMD), http://www.ks.uiuc.edu/Research/vmd/ (Accessed in 2010)

Wang C., T. Yu, W. Duan \& L.Wang (1995), A First Principles Interatomic Potential and Application to the GrainBoundary in Ni, Physics Letters A, Vol. 197, Iss. 5-6, pp 449457

Zhang J.T. , T. Sun, Y. Yan, Y. Liang \& S. Dong, Molecular Dynamics Study of Groove Fabrication Process using AFM-Based Nanometric Cutting Technique, Applied Physics A (Materials Science and Processing), Vol. 94, 2009, pp 593-600

Zhao K.J., C.Q. Chen, Y.P. Shen and T.J. Lu (2009), Molecular Dynamics Study on the Nanovoid Growth in Face-centered Cubic Single Crystal Copper, Computational Materials Science, Vol. 46, pp 749-754 


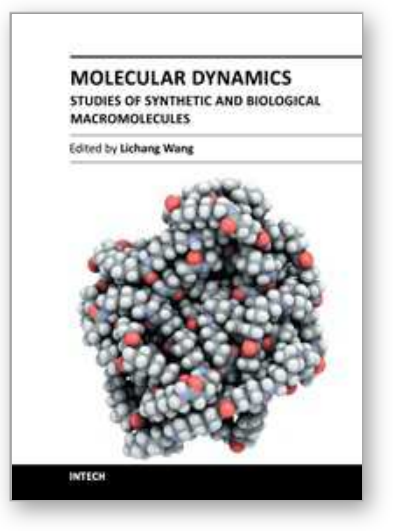

\author{
Molecular Dynamics - Studies of Synthetic and Biological \\ Macromolecules \\ Edited by Prof. Lichang Wang
}

ISBN 978-953-51-0444-5

Hard cover, 432 pages

Publisher InTech

Published online 11, April, 2012

Published in print edition April, 2012

Molecular Dynamics is a two-volume compendium of the ever-growing applications of molecular dynamics simulations to solve a wider range of scientific and engineering challenges. The contents illustrate the rapid progress on molecular dynamics simulations in many fields of science and technology, such as nanotechnology, energy research, and biology, due to the advances of new dynamics theories and the extraordinary power of today's computers. This second book begins with an introduction of molecular dynamics simulations to macromolecules and then illustrates the computer experiments using molecular dynamics simulations in the studies of synthetic and biological macromolecules, plasmas, and nanomachines. Coverage of this book includes: Complex formation and dynamics of polymers Dynamics of lipid bilayers, peptides, DNA, RNA, and proteins Complex liquids and plasmas Dynamics of molecules on surfaces Nanofluidics and nanomachines

\title{
How to reference
}

In order to correctly reference this scholarly work, feel free to copy and paste the following:

Akinjide Oluwajobi (2012). Molecular Dynamics Simulation of Nanoscale Machining, Molecular Dynamics Studies of Synthetic and Biological Macromolecules, Prof. Lichang Wang (Ed.), ISBN: 978-953-51-0444-5, InTech, Available from: http://www.intechopen.com/books/molecular-dynamics-studies-of-synthetic-andbiological-macromolecules/molecular-dynamics-simulation-of-nanoscale-machining

\section{INTECH}

open science | open minds

\author{
InTech Europe \\ University Campus STeP Ri \\ Slavka Krautzeka 83/A \\ 51000 Rijeka, Croatia \\ Phone: +385 (51) 770447 \\ Fax: +385 (51) 686166 \\ www.intechopen.com
}

\author{
InTech China \\ Unit 405, Office Block, Hotel Equatorial Shanghai \\ No.65, Yan An Road (West), Shanghai, 200040, China \\ 中国上海市延安西路65号上海国际贵都大饭店办公楼 405 单元 \\ Phone: +86-21-62489820 \\ Fax: $+86-21-62489821$
}


(C) 2012 The Author(s). Licensee IntechOpen. This is an open access article distributed under the terms of the Creative Commons Attribution 3.0 License, which permits unrestricted use, distribution, and reproduction in any medium, provided the original work is properly cited. 